\title{
Integrated systems for forecasting urban meteorology, air pollution and population exposure
}

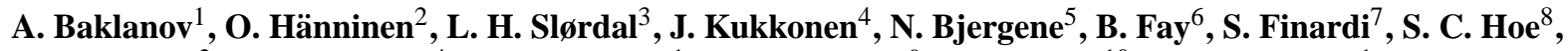 \\ M. Jantunen ${ }^{2}$, A. Karppinen ${ }^{4}$, A. Rasmussen ${ }^{1}$, A. Skouloudis ${ }^{9}$, R. S. Sokhi ${ }^{10}$, J. H. Sørensen ${ }^{1}$, and V. Ødegaard ${ }^{5}$ \\ ${ }^{1}$ Danish Meteorological Institute, DMI, Copenhagen, Denmark \\ ${ }^{2}$ Finnish National Public Health Institute, KTL, Finland \\ ${ }^{3}$ Norwegian Institute for Air Research, NILU, Norway \\ ${ }^{4}$ Finnish Meteorological Institute, FMI, Helsinki, Finland \\ ${ }^{5}$ Norwegian Meteorological Institute, met.no, Oslo, Norway \\ ${ }^{6}$ German Weather Service, DWD, Offenbach, Germany \\ ${ }^{7}$ ARIANET Consulting, Milano, Italy \\ ${ }^{8}$ Danish Emergency Management Agency, Birkerød, Denmark \\ ${ }^{9}$ Environment Institute - Joint Research Center, JRC EI, Ispra, Italy \\ ${ }^{10}$ University of Hertfordshire, UH, UK
}

Received: 4 October 2005 - Published in Atmos. Chem. Phys. Discuss.: 16 March 2006

Revised: 14 February 2007 - Accepted: 14 February 2007 - Published: 15 February 2007

\begin{abstract}
Urban air pollution is associated with significant adverse health effects. Model-based abatement strategies are required and developed for the growing urban populations. In the initial development stage, these are focussed on exceedances of air quality standards caused by high short-term pollutant concentrations. Prediction of health effects and implementation of urban air quality information and abatement systems require accurate forecasting of air pollution episodes and population exposure, including modelling of emissions, meteorology, atmospheric dispersion and chemical reaction of pollutants, population mobility, and indoor-outdoor relationship of the pollutants. In the past, these different areas have been treated separately by different models and even institutions. Progress in computer resources and ensuing improvements in numerical weather prediction, air chemistry, and exposure modelling recently allow a unification and integration of the disjunctive models and approaches. The current work presents a novel approach that integrates the latest developments in meteorological, air quality, and population exposure modelling into Urban Air Quality Information and Forecasting Systems (UAQIFS) in the context of the European Union FUMAPEX project. The suggested integrated strategy is demonstrated for examples of the systems in three Nordic cities: Helsinki and Oslo for assessment and forecasting of urban air pollution and Copenhagen for urban emergency preparedness.
\end{abstract}

Correspondence to: A. Baklanov

(alb@dmi.dk)

\section{Introduction}

Most major European conurbations experience severe shortterm pollution episodes that are harmful to the environment and to human health, especially for children and the elderly. The European Environment Agency evaluated that more than 40 million people, living in 115 major urban areas in Europe, are exposed to pollutant levels that exceed the reference levels stated by the World Health Organisation (WHO, 2000). European Union (EU) Air Quality Directives (EC/96/62, EC/99/30, EC/2000/69 and EC/2002/3) and national regulatory legislation were introduced to abate these adverse effects.

Air quality modelling, linked with population exposure evaluation, can provide a relevant support to urban air quality management and critical conditions recovery planning. These modelling tools may be applied on two temporal scales. On the one hand, short-term urban air quality forecasts are compared with air quality guidelines on a daily basis and can therefore be used to create warning systems and plan mitigation actions to prevent severe episodic situations. Short-term forecasting systems include information and emergency preparedness systems. On the other hand, air quality modelling systems are employed for long term air quality evaluation needed for urban planning, the design and management of transportation networks, industrial sites and residential areas, in order to minimise unacceptable risk to public health. 
In order to diminish or prevent risk and critical concentration levels, abatement action (such as e.g. traffic reduction) should be planned at least one or two days in advance. Often no effective action can be imposed because no or only inadequate forecasting models exist. Additionally, the possibility of terrorist acts involving dispersion of radioactive materials (e.g., dirty bombs) or actions against nuclear objects has considerably increased the need for improvement of emergency preparedness systems for urban areas, which offer a relevant contribution even to the management of accidental releases from industrial facilities (e.g. Toulouse 21 September 2001). An up-to-date air quality forecasting system should be based on an air quality model linked with a numerical weather prediction (NWP) model, and supplemented by population exposure (PE) modelling, creating a full Urban Air Quality Information and Forecasting System (UAQIFS) capable to properly describe urban scale meteorological and pollutant dispersion phenomena. Improved UAQIFS need to be verified against existing measurement data sets, and then implemented more widely in Europe for providing better protection of environment and human health in cities and urbanised regions where an ever-increasing part of the population resides.

In many European cities, integrated assessment methods, based on both measurements and models, are employed to perform the air quality assessment. These are required by the European legislation on a yearly basis. Air quality monitoring networks have been operational in the main cities and in some rural areas for many years. The use of air quality models, which have been introduced more recently, is necessary to assist decision makers in evaluating options of long-term abatement policies through the simulation of future emission scenarios. The availability of an operational UAQIFS can provide a relevant contribution to understand air pollution phenomenology observed at the monitoring stations, through proper reconstruction of atmospheric flow and pollutant dispersion features.

Historically, urban air quality forecasting and NWP models were developed separately, and there is little or no tradition for co-operation between these modelling communities. Until some years ago, the resolution of NWP data was not suitable for the urban scale, and the models did not consider urban features. The situation has now changed and a fruitful cooperation between meteorological and air quality research is anticipated. It is obvious that a revision of the conventional conception of urban air quality forecasting is required. In a general sense we suggest to consider air quality as a combination of at least the following factors: urban climate/meteorology, air pollutant dispersion, and population exposure. It is reasonable to consider them together because:

(i) meteorology is one of the main sources of uncertainty in urban air pollution and emergency preparedness models, (ii) complex and combined effects of meteorological and pollution components on human health are known (e.g., the hot summer weather events with high pollution episodes and numerous mortality cases in Paris, July 2003),

(iii) effects of pollutants/aerosols on urban climate and meteorological events (precipitation, thunderstorms, etc.) should be included.

Ambient pollutant concentrations are associated with significant health effects on urban populations (Samoli et al., 2005; Pope et al., 2002; WHO, 2000). Compliance with air quality standards, however, while being a useful administrative tool in air quality management, is nevertheless not sufficient to protect the general public from the excess morbidity and mortality currently caused by air pollution.

Exposure is the mediating link between man and the environment; the health effects actually having a causal association with air pollution must be caused by personal exposures of the affected individuals (Ott, 1995). Personal exposures have been, however, found to correlate poorly with ambient air quality (Kousa et al., 2002a; Koistinen et al., 2001; Oglesby et al., 2000; Pellizzari et al., 1999). Personal exposures differ from ambient air quality, as characteristically a majority of time is spent in indoor environments, where the building envelope filters some of the ambient pollution, and indoor pollution sources affect air quality. The presence of individuals in the vicinity of the emission sources, especially in traffic, may also substantially increase exposure, compared with the data at fixed monitoring sites. As a result, air quality modelling needs to be integrated with population time-activity and mobility models to estimate actual exposure distributions caused by ambient pollution even in situations when ambient air quality standards are met. This is one of the main objectives of the current work.

The main novel element of this paper is the presentation of an improved type of UAQIFS which integrates all the required forecast steps from emissions and meteorological data to atmospheric pollution and population exposure. The previous experience and corresponding publications suggested some integrated systems: starting from atmospheric dispersion models integrated with population exposure models for environmental assessments (e.g., Coulson et al., 2005) or from meteorological models to atmospheric pollution forecast for urban areas without consideration of the health effects (e.g., Berge et al., 2002; Byun and Ching, 1999). For emergency preparedness modelling there exist integrated systems, which consider NWP model data, accidental contamination and population doses, but they consider mostly regional scale processes and do not include urban features, e.g. the urban meteorology (e.g., RODOS, 2000).

Here we present for the first time an integrated system encompassing emissions, urban meteorology and population exposure for urban air pollution episode forecasting, the assessment of urban air quality and health effects, and for 
emergency preparedness issues for urban areas. Such integration increases the quality of the air pollution forecast in urban areas. It further provides the opportunity to consider combined effects of meteorological and pollution factors, and provides important data for decision makers and information about the health risk in the form of population exposure. Thus, the system is directly geared to the final product and main issue: the people health danger and population exposure.

\section{FUMAPEX methodology of improved UAQIFS, inte- grated from meteorology to population exposure}

\subsection{General structure of the UAQIFS}

The main aim of the FUMAPEX project is to develop, evaluate, and disseminate improved urban air quality information and forecasting systems enhancing the capabilities to successfully describe and predict air contamination episodes in cities of different European regions. This is achieved through improvement and integration of systems for forecasting urban meteorology, air pollution, and population exposure based on modern information technologies.

The outline of the overall FUMAPEX methodology of integrating models from urban meteorology to air quality and population exposure for the improved UAQIFS is presented in Fig. 1.

Forecasting urban air quality (UAQ) and health effects is divided into four integrated steps:

1. the application of national weather forecasts of the synoptic situation and meteorological fields/parameters,

2. the downscaling of city-scale meteorological model results for urban meteorology forecasts, the postprocessing of NWP data for urban air pollution (UAP) model input,

3. the computation of pollutant concentrations, using urban dispersion modelling systems,

4. the calculation of population (individual and collective) exposures or doses, using probabilistic or deterministic models.

The improved urban-scale meteorological and air quality models are integrated in the UAQIFS (see Fig. 1) with modelling of population activity, including time spent indoors, outdoors, and in traffic, to estimate population exposures.

Air quality modelling, linked with population exposure simulations, is useful on two temporal scales. On the one hand, daily urban air quality is compared to air quality guidelines; short-term forecasts of air quality may therefore be used for warning systems and targeting actions in episode situations. Such short-term forecasts are also required in emergency preparedness systems. On the other hand, air quality

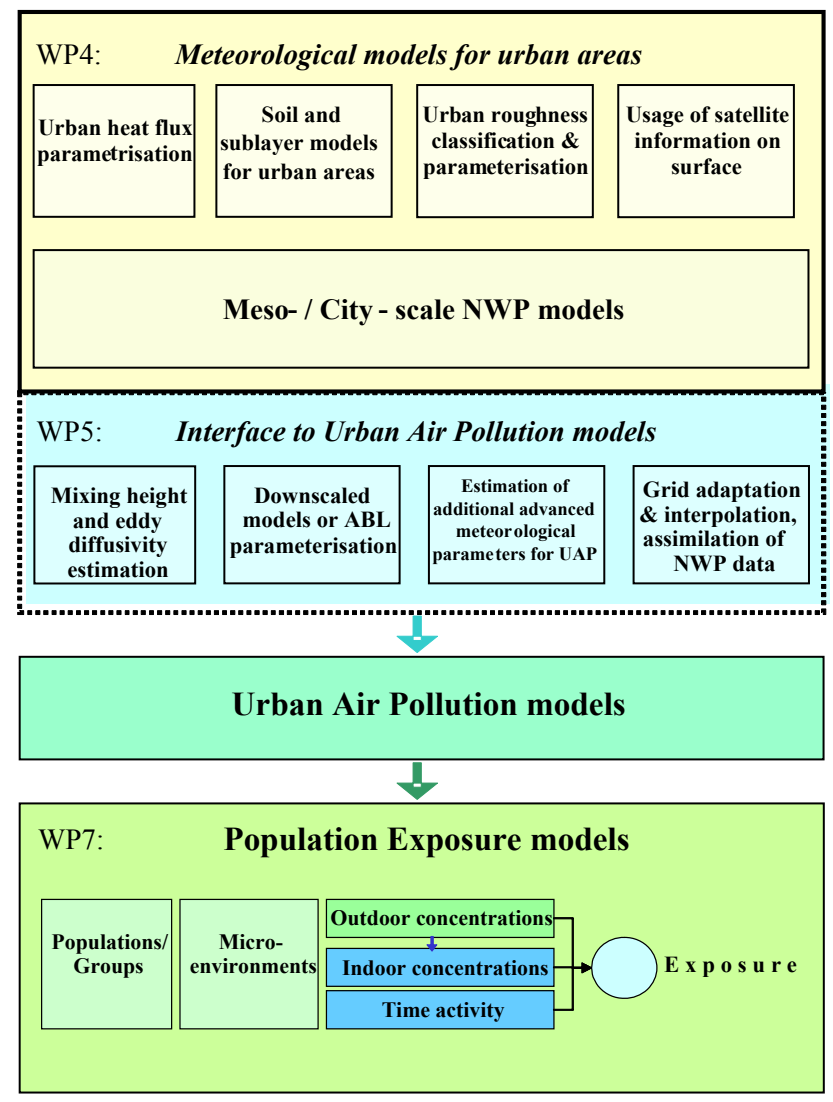

Fig. 1. Outline of the overall FUMAPEX methodology integrating models from urban meteorology to air quality and population exposure. The main improvements in meteorological forecasts (NWP) for urban areas, interfaces and integration with urban air pollution (UAP) and population exposure (PE) models for the Urban Air Quality Information Forecasting and Information Systems (UAQIFS) are mentioned in the scheme.

models are needed for longer-term urban planning, in designing transportation systems, industrial settings, and residential areas in a way that minimises unacceptable risks to public health. Therefore, these modelling approaches are utilised in both short-term forecasts of air quality, combined with episode specific air quality management, and in long-term urban air quality planning.

The realisation of the system depends on the specific features of the city, its geographic and topographic location, and the climatological and air quality problems that affect the area. In the context of the FUMAPEX project the improved integrated UAQIFS is implemented in six target cities: Oslo (Norway), Turin (Italy), Helsinki (Finland), Castellon/Valencia (Spain), Bologna (Italy), Copenhagen (Denmark). For those target cities, the developed systems differ considerably and are realised in one or more of the following modes:

1. urban air quality forecasting mode, 
2. urban management and planning mode,

3. public health assessment and exposure prediction mode,

4. urban emergency preparedness mode.

This paper focuses on both the forecasting and assessment modes, where they include the complete integration from meteorology to population exposure. Therefore, only three Nordic cities are considered in the paper as examples to demonstrate the capability and performance of the approach: Helsinki and Oslo for urban air pollution and Copenhagen for urban emergency preparedness.

A more general description of the UAQIFS elements is provided in Sects. 2.2-2.4, that deal with meteorological models and interfaces (Sect. 2.2), urban air quality models (Sect. 2.3), and population exposure models (Sect. 2.4). Specific details of the considered UAQIFSs for each of the cities and examples of episode forecasts for the different city UAQIFSs are reported in Sect. 3.

\subsection{Meteorological models and interfaces}

Given that European countries have different policies and practices regarding their national weather services the FUMAPEX project does not consider a unique single European meteorological model for the integrated UAQIFSs as a common European approach. The main strategy is the improvement of existing national NWP systems for higherresolution forecasting of urban meteorology with the necessary model downscaling and interfacing for UAP model input data.

In the first step, four major meteorological forecast models, operational in Europe in several modified versions (HIRLAM, Lokalmodell, MM5 and RAMS), were downscaled to about $1 \mathrm{~km}$ horizontal resolution and also increased in vertical resolution, but without improvements in physiographic parameters or physical parameterisations. They were evaluated and inter-compared for up to 8 pollution episodes in Oslo, Helsinki, Bologna and Valencia (selected results in Fay and Neunhäuserer, 2006; Fay et al., 2004, 2005). Oneand two-way nested high-resolution simulations led to some improvement for cities especially in inhomogeneous terrain like mountainous or coastal regions which applies to all three target cities considered in this study. Deficiencies remain especially for extreme wintertime inversion episodes which are experienced in Northern Europe in rural and urban environments alike. During these extreme episodes in Helsinki and Oslo, inversion intensity and atmospheric stability tend to be underpredicted in most models leading to underprediction of urban pollutant levels. The solution of these general NWP deficiencies, including enhanced assimilation of meteorological observations, will improve the successful application of NWP results in the urban environment also.

Additionally meteorological models used for weather prediction do not account for the micrometeorological phenomena caused by the urban structures in densely populated areas which are not required for forecasting the overall weather. These phenomena, however, are crucial for forecasting urban air quality. Therefore, in the second step, further improvements in NWP models for the urban scale were realised for NWP models used in several European countries. These include the development and application of high-resolution urban physiographic parameters and of urbanised physical parameterizations especially in the urban sublayer, and the simulation of internal boundary layers and mixing heights in urban areas. Successful improvements include the reclassification of land-use categories with additional urban classes in HIRLAM, RAMS and MM5, the definition of urbanised physiographic parameters and anthropogenic heat fluxes in HIRLAM and Lokalmodell, and the application of an urbanised soil and sublayer model in HIRLAM and MM5 (see details in Baklanov et al., 2005a).

Additionally, NWP models are not primarily developed for air pollution and emergency modelling, and their results need to be modified or complemented to serve as input to urban and meso-scale air pollution and emergency preparedness models. Therefore, several interface modules for adapting and enhancing the operational NWP data for use in UAQ models were developed (Finardi et al., 2005). Two possible urbanisation strategies clearly emerged in the course of FUMAPEX progress: the urbanisation of the driving NWP model or the use of urban turbulence parameterisations to urbanise NWP results above the cities in a post-processing step. Both possibilities were explored and different options implemented in the target city UAQUIFSs. The first approach is in principal more scientifically sound as it allows consistent modelling of urban scale flow and turbulence and minimises the interface module task to the evaluation of dispersion parameters. It turned out difficult to implement, however, in operational NWP systems due to differing internal model organisation and the need for stable and fast results. The second approach corresponds to the re-computation of the boundary layer structure with a possible implementation of urbanised soil, surface and mixing height parameterisations inside the interface module. This method does not guarantee the full consistency of the modelled atmospheric flow but is much easier to implement, generalised and independent of a particular NWP model. An intermediate approach was also verified using a small scale urban flow model to re-evaluate the urban flow starting from the standard NWP forecast fields (Baklanov et al., 2005a).

The application of NWP models in the UAQIFSs in Oslo, Copenhagen and Helsinki shows many similarities. All national NWP models use global weather forecasts of the European Centre for Medium Range Weather Forecasts (ECMWF) in Reading, UK. These are downscaled to a final resolution below $10 \mathrm{~km}$ (for Helsinki only in an experimental version) using 2 to 4 NWP model nests including the national HIRLAM versions (and a version of the non-hydrostatic NWP model MM5 in Oslo and for Helsinki experiments). The interfaces to UAQ models differ more widely in ap- 
proach, scope and in the use of NWP results and/or meteorological observations according to the input data requirements of the varying UAQ models employed. These NWP models and meteorological interface modules are simulated at the respective national meteorological services while the UAQ and PE models are mainly operated at a separate national agency. The NWP and interface systems are described in more detail in Sect. 3 for the three cities considered in this paper.

\subsection{Urban Air Quality models}

Several UAP model types, including the Lagrangian, Eulerian, Hybrid Lagrangian/Eulerian, Gaussian, Trajectory, Box, and statistical approaches, have been considered within the FUMAPEX project with the aim of analysing the needs of UAQIFSs and their current or potential applications in different European cities. A survey of some meteorological and air pollution models available within Europe is given by Sokhi et al. (2003). The UAP models have been grouped in four main classes starting from their general features and from their meteorological input need, in order to identify the kind of processing of meteorological data that the interface modules have to perform (Finardi et al., 2005). The first class includes statistical models that do not need any calculation from the interface system. They simply require single-valued meteorological data extracted from the coupled meteorological model.

A second more numerous class of "simple" models includes all the approaches based on a steady-state solution of the dispersion equations. These models require meteorological data for a single point or possibly a vertical profile and the evaluation of Monin-Obukhov turbulence scaling parameters. Even if the interface module computations required by the previous classes are quite limited the extraction of 1-D meteorological data representative of conditions assumed to be uniform over the whole urban area is quite critical especially for large cities located in complex terrain.

The third class includes all the 3-D models based on Lagrangian descriptions of dispersion phenomena. These models need: 3-D fields of average quantities like wind, temperature, humidity and possibly turbulent kinetic energy; 2-D surface fields like precipitation, sensible heat flux, friction velocity and Monin-Obukhov length; 3-D turbulence fields, like wind variances and Lagrangian time scales, that have to be evaluated from mean variables or reconstructed from boundary layer scaling parameters.

The remaining class includes 3-D Eulerian models, that need the 3-D average meteorological fields already listed for Lagrangian models and 3-D eddy diffusivities. The Eulerian dispersion coefficients $\left(\mathrm{K}_{H}, \mathrm{~K}_{Z}\right)$ produced by NWP models can be directly used in these models. Nevertheless this practise is not always possible or advisable, and therefore the interfaces for Eulerian models are usually implemented with capabilities to re-compute turbulence parameters from mean meteorological variables and scaling pa- rameters. Among all the types of models presently used for air quality management and forecasting in urban areas, a selected number have been considered for improved UAQUIFSs being developed within FUMAPEX project. In brief, the latest-generation steady-state models (Helsinki and Bologna) and Eulerian Chemical Transport Models (Oslo, Turin, London, and Castellon/Valencia) have been implemented into the respective air quality forecasting system, while Lagrangian models are used for emergency preparedness systems (Copenhagen).

The three Nordic cities considered provide examples of the UAQIFS integration of the different kinds of UAQ models which are shortly described in Sect. 3.

\subsection{Population exposure models}

Health effects associated with air pollution are caused by actual exposures of population members. Exposures are affected by air pollution concentrations, but are modified by individuals moving around the urban area throughout their daily activities and spending a substantial portion of their time indoors, where the buildings shield some of the ambient pollution. Integration of these phenomena within the urban air quality assessment and forecasting is the main target of population exposure modelling.

Complementary approaches to exposure modelling are developed in parallel in different target cities and even within the same target cities, depending on the aspects of exposure that are of special interest locally. Regional aspects affect e.g. the selection of target pollutants and relevant target population groups. In central European and Mediterranean areas, ozone poses a much larger problem than in the Nordic areas. NO and VOC emissions are tightly associated with the generation of ozone in photochemical processes. In the Nordic countries, on the other hand, typical air quality problems include the spring dust situations, where $\mathrm{PM}_{10}$ concentrations rise during dry days through suspension of coarse particles. Traffic is recognised as the primary source of air quality problems all over Europe. Accidental or other emergency releases may include a broad spectrum of harmful radioactive, chemical, and biological species.

The local approaches to exposure modelling in some of the target cities are compared in Table 1. Based on the computational technique the approaches are classified into probabilistic and deterministic; according to the selected type of modelling of population time-activity the latter can be further divided into statistical and individual sub categories. Probabilistic models describe the probability distributions of selected exposure variables within a defined target population. Deterministic models use air quality data in a geographical format, where the ambient air concentrations are presented in a three- (or two-) dimensional space and time. The statistical version of the deterministic exposure modelling allocates populations into this spatiotemporal air quality field typically using grids and population-based estimates of numbers of 
Table 1. Comparison of exposure modelling approaches in the target cities.

\begin{tabular}{|c|c|c|c|c|c|c|c|c|c|c|}
\hline & \multicolumn{2}{|c|}{ Deterministic - individual } & \multicolumn{4}{|c|}{ Deterministic - statistical } & \multicolumn{4}{|c|}{ Probabilistic } \\
\hline & Copenhagen & Oslo Det/indiv & Copenhagen & Helsinki Det/pop & Oslo Det/pop & $\begin{array}{l}\text { Valencia \& } \\
\text { Castelón }\end{array}$ & Bologna & Helsinki Prob & London & Torino \\
\hline Geographical area & city/country & metropolitan area & city/country & $\begin{array}{l}\text { metropolitan area ( } 4 \\
\text { cities) }\end{array}$ & metropolitan area & two provinces & $\begin{array}{l}\text { metropolita } \\
\mathrm{n} \text { area }\end{array}$ & $\begin{array}{l}\text { metropolitan } \\
\text { area (4 cities) }\end{array}$ & Hertfordshire & $\begin{array}{l}\text { metropolitan } \\
\text { area }\end{array}$ \\
\hline Population, total & $0.5 \mathrm{M} / 5.4 \mathrm{M}$ & $0.5 \mathrm{M}$ & $0.5 \mathrm{M} / 5.4 \mathrm{M}$ & $1 \mathrm{M}$ & $0.5 \mathrm{M}$ & $2.2 \mathrm{M}$ & $0.4 \mathrm{M}$ & $1 \mathrm{M}$ & $1 \mathrm{M}$ & $0.9 \mathrm{M}$ \\
\hline \multicolumn{11}{|l|}{ Pollutant(s)/urban air } \\
\hline PM & radionuclides & $\mathrm{PM}_{10}, \mathrm{PM}_{2.5}$ & radionuclides & $\mathrm{PM}_{2.5}$ & $\mathrm{PM}_{10}, \mathrm{PM}_{2.5}$ & - & $\mathrm{PM}_{10}$ & $\mathrm{PM}_{2.5}$ & $\mathrm{PM}_{10}, \mathrm{PM}_{2.5}$ & $\mathrm{PM}_{10}$ \\
\hline gaseous & $\overbrace{}^{\text {radionuclides }}$ & $\mathrm{NO}_{2}$ & $\subsetneq^{\text {radionuclides }}$ & $\mathrm{NO}_{2}$ & $\mathrm{NO}_{2}$ & $\mathrm{O}_{3}$ & $\mathrm{NO}_{2}$ & $\mathrm{NO}_{2}$ & $\mathrm{NO}_{2}$ & $\mathrm{O}_{3}, \mathrm{NO}_{2}$ \\
\hline Pollutant(s)/exposure & 可 $\alpha, \beta, \gamma$ & $\begin{array}{l}\mathrm{PM}_{10}, \mathrm{PM}_{2.5}, \mathrm{PM}_{1} \\
\mathrm{NO}_{2}\end{array}$ & 疍 $\alpha, \beta, \gamma$ & $\mathrm{PM}_{2.5}, \mathrm{NO}_{2}$ & $\mathrm{PM}_{10}, \mathrm{PM}_{2.5}, \mathrm{NO}_{2}$ & $\mathrm{O}_{3}$ & $\mathrm{PM}_{2.5}, \mathrm{NO}_{2}$ & $\mathrm{PM}_{2.5}$ & $\mathrm{NO}_{2}$ & $\mathrm{PM}_{10}, \mathrm{NO}_{2}, \mathrm{O}_{3}$ \\
\hline Exposure model approach & $\begin{array}{l}\text { GIS, individual } \\
\text { doses }\end{array}$ & GIS, individual & $\begin{array}{l}\text { Deterministic, } \\
\text { collective } \\
\text { doses }\end{array}$ & $\begin{array}{l}\text { Deterministic, } \\
\text { statistical population }\end{array}$ & $\begin{array}{l}\text { Stationary } \\
\text { residences }\end{array}$ & $\begin{array}{l}\text { Stationary, } \\
\text { community } \\
\text { level }\end{array}$ & Probabilistic & Probabilistic & Probabilistic & Probabilistic \\
\hline Population groups & $\begin{array}{l}\text { individuals, } 3 \\
\text { groups }\end{array}$ & $\begin{array}{l}\text { selected } \\
\text { individuals }\end{array}$ & $\begin{array}{l}\text { general, } 3 \\
\text { groups }\end{array}$ & $\begin{array}{l}\text { working age, infants, } \\
\text { elderly }\end{array}$ & $\begin{array}{l}\text { general } \\
\text { population }\end{array}$ & $\begin{array}{l}\text { general } \\
\text { population }\end{array}$ & children & $\begin{array}{l}\text { working age, } \\
\text { infants, elderly }\end{array}$ & $\begin{array}{l}\text { a sample of } \\
\text { office workers }\end{array}$ & children, elderly \\
\hline $\begin{array}{l}\text { Processing of spatial time- } \\
\text { activity information }\end{array}$ & GIS & GIS & GIS & GIS & GIS & muncipalities & $\begin{array}{l}\text { statistical } \\
\text { sampling }\end{array}$ & $\begin{array}{l}\text { statistical } \\
\text { sampling }\end{array}$ & $\begin{array}{l}\text { population } \\
\text { sample }\end{array}$ & grid \\
\hline Time frame & episode hourly & $\begin{array}{l}\text { 1) hourly } \\
\text { 2) daily }\end{array}$ & $\begin{array}{l}\text { episode, } \\
\text { integrated }\end{array}$ & $\begin{array}{l}\text { 1) hourly } \\
\text { 2) selected averages }\end{array}$ & $\begin{array}{l}\text { 1) hourly } \\
\text { 2) selected } \\
\text { averages }\end{array}$ & $\begin{array}{l}\text { 1) daily } \\
\text { 2) annual }\end{array}$ & school year & $\begin{array}{l}\text { 1) annual } \\
\text { 2) episode } \\
\text { days }\end{array}$ & $\begin{array}{l}\text { measurement } \\
\text { periods ( } 7 \\
\text { days) }\end{array}$ & daily \\
\hline Microenvironment categorie & $\begin{array}{l}\text { residence, } \\
\text { workplace, } \\
\text { nutrition } \\
\text { pathways }\end{array}$ & $\begin{array}{l}\text { residence, } \\
\text { workplace, traffic, } \\
\text { indoors, outdoors }\end{array}$ & $\begin{array}{l}\text { districts, } \\
\text { residence, } \\
\text { workplace, } \\
\text { nutrition } \\
\text { pathways }\end{array}$ & $\begin{array}{l}\text { residence, } \\
\text { workplace, other } \\
\text { indoors, other } \\
\text { outdoors, traffic }\end{array}$ & residence & $\begin{array}{l}\text { indoors, } \\
\text { outdoors }\end{array}$ & $\begin{array}{l}\text { residence, } \\
\text { outdoors }\end{array}$ & $\begin{array}{l}\text { residence, } \\
\text { workplace, } \\
\text { other indoors, } \\
\text { other outdoors, } \\
\text { traffic }\end{array}$ & $\begin{array}{l}\text { residence, } \\
\text { workplace, } \\
\text { other indoors, } \\
\text { other } \\
\text { outdoors, } \\
\text { traffic }\end{array}$ & $\begin{array}{l}\text { residence, } \\
\text { outdoors }\end{array}$ \\
\hline Infiltration modelling & fixed factor & $\begin{array}{l}\text { modelled based } \\
\text { on building age, } \\
\text { wind speed and } \\
\text { temperature }\end{array}$ & fixed factor & fixed factor & unity & fixed factor & $\begin{array}{l}\text { probabilistic } \\
\text { /fixed factor }\end{array}$ & probabilistic & probabilistic & fixed factor \\
\hline Exposure unit of measure & Sv & $\mu \mathrm{g} \mathrm{m}^{-3}$ & person $x$ Sv & person $\times \mathrm{h} \times \mu \mathrm{g} \mathrm{m}^{-3}$ & $\begin{array}{l}\text { Number of } \\
\text { persons exposed } \\
\text { to each } A Q \\
\text { category }\left(\mu \mathrm{g} \mathrm{m}^{-3}\right)\end{array}$ & $\mu \mathrm{g} \mathrm{m}^{-3}$ & $\mu \mathrm{g} \mathrm{m}^{-3}$ & $\mu g \mathrm{~m}^{-3}$ & $\mu \mathrm{g} \mathrm{m}^{-3}$ & $\mu g \mathrm{~m}^{-3}$ \\
\hline
\end{tabular}

people residing within the grid area. The individual deterministic model uses spatial time-location data to consider specific individuals in time and space.

The probabilistic and statistical/deterministic approaches are suitable for the estimation of exposures of the general population and large population sub-groups. The individual deterministic model requires, on the one hand, very detailed data on specific individuals and is thus limited to selected persons and periods. Probabilistic and individual deterministic models may be used to estimate exposures as timeweighted average concentrations. The deterministic model with a statistical population, on the other hand, can only be used to estimate the population average exposure concentration; within the model grid exposures are measured using number of persons $\times$ hours (or another relevant measure of time) $\times$ concentration.

The most simple time activity models do not take into account population mobility or pollution infiltration indoors. Such models allocate populations to the air quality field typically using coordinates of residential buildings (e.g. Oslo) or use community level air quality to estimate exposures in larger areas (e.g. Valencia). Estimates based on outdoor air quality at residential locations are relevant especially for preschool children and elderly (retired). On the other hand, the exposures of school children and the working age population, which both spend substantial amounts of their time in alternative locations and in traffic, are not very well characterized by such estimates.

The probabilistic approach is by definition well suited to describing the variability in exposures caused by population time-activity and variable infiltration of pollution in different indoor spaces (Hänninen et al., 2004). The probabilistic modelling technique has also been specially developed for prediction of changes in exposures in future scenarios accounting for selected environmental policies (Hänninen et al., 2005). The deterministic models are typically forced to use estimated population average infiltration factors at best due to the complexity of infiltration in individual buildings reducing variability of the exposure estimates. In Helsinki, the deterministic approach has been developed into taking into account the population mobility within the city and infiltration of $\mathrm{PM}_{2.5}$ into indoor microenvironments. The statistical approach to the population modelling used in this model, however, does not follow specific individuals from one hour 
to another, and therefore only population average exposures can be estimated for periods longer than one hour. Distributions of daily or longer personal exposures cannot be estimated beyond the spatial dimension.

Due to the focus of the Copenhagen system on emergency preparedness, the calculation of population exposure in ARGOS has significant specifics, considered in Sect. 3.3.

\section{Applications of the improved integrated systems}

Implementation and test of the improved integrated UAQIFS in FUMAPEX is realised for six main target cities (Oslo, Turin, Helsinki, Castellon/Valencia, Bologna, Copenhagen) and partly for London and Paris. In this section we will illustrate the practical realisation and functioning of the systems in the three Nordic capitals considered: Helsinki, Oslo, and Copenhagen, because they applied the improved system in the full integration: from the meteorology to population exposure.

\subsection{Helsinki UAQIFS}

The UAQ modelling system for the Helsinki Metropolitan Area is based on a multi-scale model cascade; the background concentrations for local scale dispersion models may be evaluated either using regional scale dispersion models, or from regional background measurements. The local scale dispersion modelling is based on a combined application of the road network dispersion model CAR-FMI (e.g., Härkönen, 2002), the Operational Street pollution model OSPM (e.g., Berkowicz, 2000; Kukkonen et al., 2003) and the Urban Dispersion Model UDM-FMI (Karppinen et al., 2000a, b), regarding dispersion from streets and roads, dispersion in a street canyon, and dispersion from various point, area and volume sources, respectively.

The modelling system also includes the estimation of traffic flows, and emissions for stationary and vehicular sources, a meteorological pre-processing model, chemical transformation models, a deterministic population exposure model, and the statistical and graphical analysis of the computed times series of concentrations (Karppinen et al., 2000a, b). Aerosol process models $\mathrm{n}$ also be utilised in combination with the modelling system (e.g., Pohjola et al., 2003).

The meteorological input is obtained from the operational NWP model HIRLAM, which is a hydrostatic limited area grid model. The boundary values are extracted from the global ECMWF NWP model once in every three hours (Kangas and Sokka, 2005). A meso- $\beta$ scale model suite is also executed operationally (Järvenoja, 2005). The horizontal resolution of the latter model is $9 \mathrm{~km}$. Both the original and the meso- $\beta$ scale HIRLAM variants are coupled to the UAQ modelling system.

For long-term air quality assessments, the meteorological input parameters for the local-scale models can alter- natively be evaluated in the meteorological pre-processing model MPP-FMI (Karppinen et al., 1997). The model has been adapted for an urban environment (Karppinen et al., 2000c); this model is originally based on the energy budget method of van Ulden and Holtslag (1985). The model utilises meteorological synoptic and sounding observations, and its output consists of estimates of the hourly time series of the relevant atmospheric turbulence parameters and the boundary layer height.

The EXPAND model (EXposure model designed especially for Particulate matter And Nitrogen oxiDes) is used for the determination of human exposure to ambient air pollution in an urban area (Kousa et al., 2002b). The EXPAND model combines the predicted concentrations and the information on time use of the population at different locations. The computed results are processed and visualised using GIS. We have also included the infiltration of pollutants into indoor microenvironments into the model. The latest model version also allows for the use of hourly time-activity, concentration, and other data, and it includes a detailed treatment of various traffic modes.

A major advantage of the deterministic population exposure modelling approach is that the results can be processed and presented spatially using GIS techniques. The EXPAND model has been designed only for evaluating population average exposures. A limitation of the model is that the location and movements of specific individuals cannot be temporally followed.

The probabilistic EXPOLIS model represents a different kind of approach for modelling population exposure. This model uses statistical sampling to collapse the geographical dimension of concentrations, and applies probabilistic microenvironment time-activity model, including probabilistic modelling of infiltration of outdoor pollution indoors, in order to estimate distributions of personal daily exposure levels, measured as time-weighted exposure concentrations (i.e. $\mu \mathrm{gm}^{-3}$ ) (Kruize et al., 2003; Hänninen et al., 2003, 2005). The main advantage of the probabilistic approach is that the simulated individuals are followed over the selected averaging period and therefore the distribution of, e.g., daily exposures can be estimated. In combination with doseresponse knowledge, this allows for a detailed quantification of health risks within selected population groups.

Both the deterministic and probabilistic approaches use building registry data to locate residences, workplaces, and other places of activity, and population time-activity data to allocate population time into these environments and into the various modes of traffic and transportation. The EXPAND model handles this information geographically using a GIS system. Population time-activity is modelled statistically, and allocated into a numerical grid of a resolution of $100 \times 100 \mathrm{~m}^{2}$. After combining this information with the numerical predictions of air quality, the model can be utilised for presenting both hourly snapshots and longer-term averages of the spatial distributions of population exposures, 

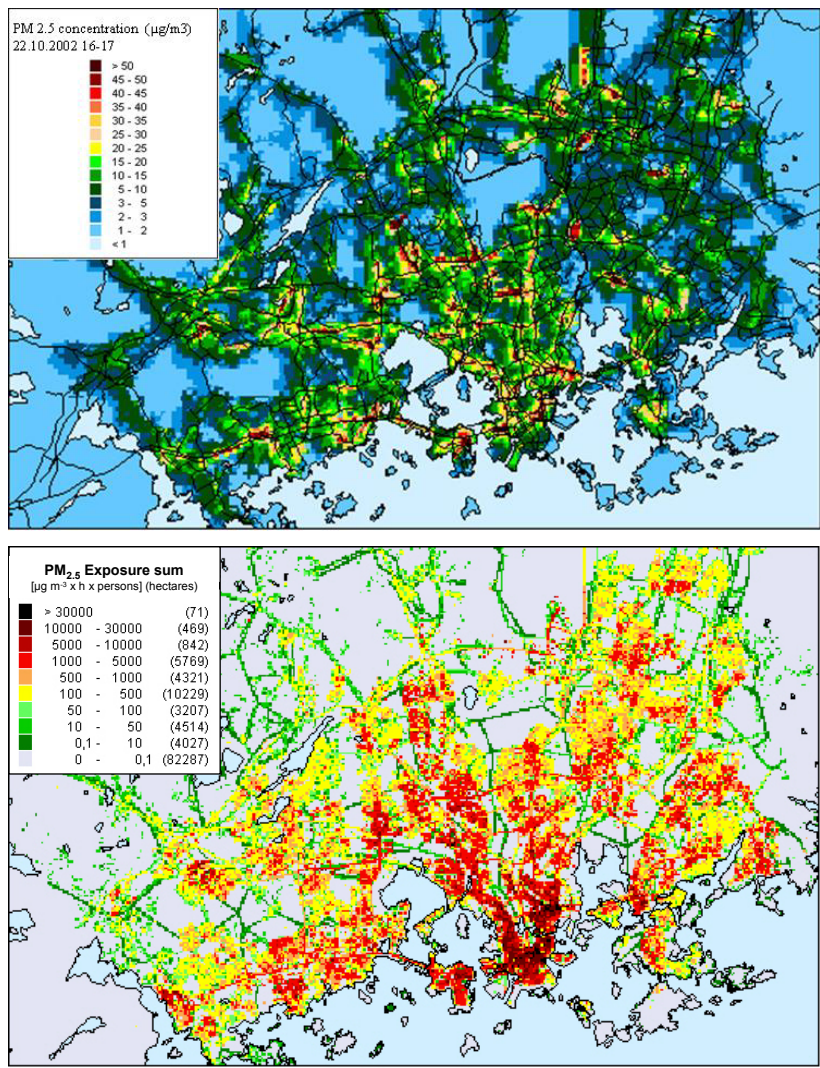

Fig. 2. Predicted spatial distribution of the concentrations of $\mathrm{PM}_{2.5}$ in the Helsinki metropolitan area during an afternoon rush hour (from 04:00 to 05:00 p.m.; upper map), and the daily population exposure to $\mathrm{PM}_{2.5}$, computed with the EXPAND model (lower map), both of these in the course of a peak pollution episode on 22 October 2002. The episode was mainly caused by stable atmospheric stratification combined with a strong ground-based temperature inversion.

represented as the product of the sum of persons, temporal durations and concentrations.

Selected numerical results of these exposure models in the greater Helsinki area are presented in the following, in order to illustrate the practical applications of the models. Examples of the spatial distributions of the $\mathrm{PM}_{2.5}$ concentrations and population exposures are presented in Figs. 2a-b, computed by the above mentioned urban modelling system and the EXPAND model, respectively. The values correspond to a selected air pollution episode. The numerical results may be utilised, e.g., in planning potential practical measures to be taken in the course of extremely severe episodes, or in evaluating the influence of air pollution episodes on the health of the population.

Uncertainties in the population exposure estimates involve two components: uncertainties in the estimated outdoor air quality, and uncertainties in the ambient air-exposure relationship (the exposure model). The Helsinki UAQIFS has been validated separately for the air quality forecasting and population exposure estimation. The air quality model performance has been estimated for $\mathrm{PM}_{2.5}$ vs. yearly data from six monitoring stations in the Helsinki metropolitan area (Karppinen et al., 2005). Figure 3a shows the model performance during year 2002 at Kallio monitoring station, where daily average levels are satisfactorily reproduced. Overall annual model performance is substantially better than during the episode conditions. Evaluation of air quality model performance during autumn 2002 at Vallila monitoring station (Fig. 3b) shows also a satisfactorily reproduction on daily average levels.

The probabilistic exposure model was evaluated against personal exposure measurements collected in the EXPOLIS study in 1996-1997 in Helsinki (Jantunen et al., 1998; Hänninen et al., 2004a). The model, using actual concentration distributions observed outdoors at residential locations of the random population sample and infiltration factors analyzed from elemental analysis of the $\mathrm{PM}_{2.5}$ samples (Hänninen et al., 2004b), was able to capture the overall range of personal exposures in the working age population and for most exposure percentiles the model error was below $10 \%$ or $2 \mu \mathrm{g} / \mathrm{m}^{3}$. Above the 90 th percentile the model error peaked to approximately $30 \%$ corresponding to $10 \mu \mathrm{g} / \mathrm{m}^{3}\left(8-12 \mu \mathrm{g} / \mathrm{m}^{3}\right.$ depending on the model version) (Fig. 3c)(Hänninen et al., 2005).

In the current work errors in estimating the spatial and temporal variability of ambient concentrations during the selected episode days was handled by modifying the predicted ("raw") air quality values using observed data from the air quality monitoring network to get the best estimates of true population exposures. The difference between the raw and corrected exposures was substantial (Fig. 3d). For all the studied four episode days the air quality model underestimated the levels at the monitoring sites. During the longrange transport episodes an equal surface was added, supported by the comparison of observed levels at Kallio and Vallila monitoring stations (data not shown). For the locally generated inversion (Fig. 3d) and spring dust episodes (data not shown) it was assumed that the error term was relative and all predicted ("raw") levels were multiplied by the ratio observed/predicted level at the Vallila monitoring site. The remaining spatial error term after this correction can be evaluated using observations from the Kallio site; the corrected prediction ranged from $94 \%$ (6\% underestimation; wildfire associated long-range transported episode) to $117 \%(17 \%$ overestimation; inversion case)(Fig. 3d).

Thus the overall relative model error is a combination of two modest components, both below $10 \%$ in most cases but approaching $20-30 \%$ in the observed extremes in the current study. All extremes being underestimations; when combined $(1.2 \times 1.3)$ these would lead to approximately $50 \%$ underestimation in the highest ten exposure percentiles $(1.2 \times 1.3=1.56$, error $56 \%)$. This estimate of the uncertainty in the results is depicted in Fig. 3d in gray on top of the model result. 

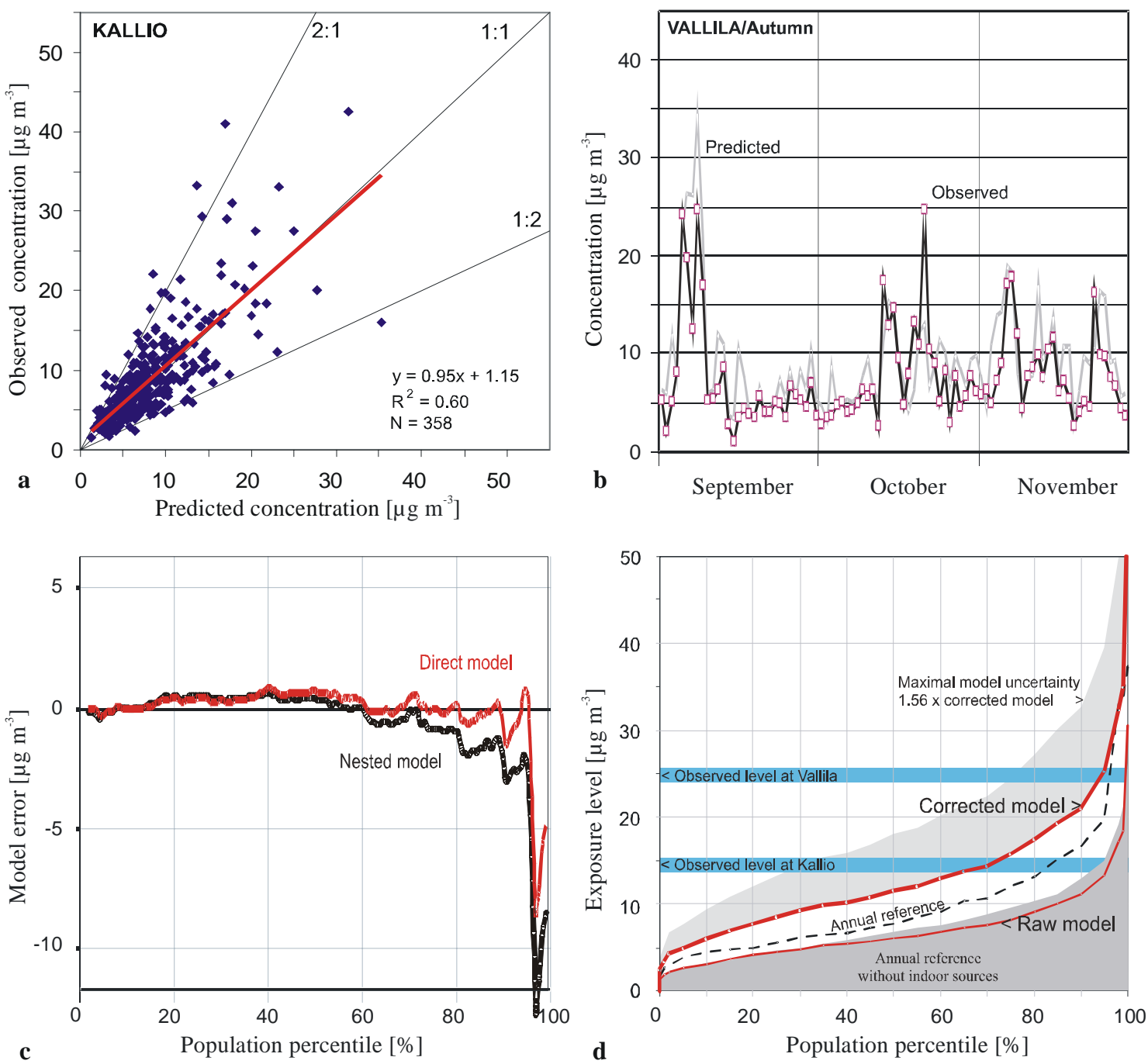

Fig. 3. Long-term evaluation of the Helsinki UAQIFS for the air quality (a, b) and population exposure (c, d): (a) during year 2002 at Kallio monitoring station; (b) during autumn 2002 at Vallila monitoring station. (c) Model error in microenvironment-based probabilistic simulation of population exposures (Hänninen et al., 2005). Direct model uses measured indoor concentrations while nested model is based on modeling of infiltration of outdoor concentrations indoors and indoor sources. (d) Exposure distribution of the Helsinki metropolitan area working age population during an inversion episode day (22 October 2002) and the corresponding observed levels at two fixed monitoring stations. Annual reference displays the distributions of daily exposures of working age population over one year period with and without the contribution of indoor sources.

\subsection{Oslo UAQIFS}

The meteorological forecast system applied in the Oslo UAQIFS consists of the operational regional NWP model HIRLAM (Undén, 2002) and the meso-scale (nonhydrostatic) meteorological model MM5 (Dudhia, 1993, 1996; Grell et al., 1994). This model system is operated offline coupled with the UAP model AirQUIS (AirQUIS, 2005) through a meteorological pre-processor interface program.

The Norwegian Meteorological Institute (met.no) provides meteorological forecasts for Norway, Northern-Europe and the adjacent ocean areas. For this purpose the HIRLAM models with $20 \mathrm{~km}$ resolution (HIRLAM20), $10 \mathrm{~km}$ resolution (HIRLAM10) and $5 \mathrm{~km}$ resolution (HIRLAM5) are applied in operational mode, HIRLAM20 up to 4 times a day. HIRLAM10 results are used as initial and boundary conditions for the MM5 model (Berge et al., 2002). The operational MM5 configuration consists of an outer $3 \mathrm{~km}$ horizontal resolution grid and an inner mesh with $1 \mathrm{~km}$ horizontal resolution, covering quite a large area around Oslo. The MM5 horizontal grid is made up of $88 \times 76$ grid points. Both integration areas consist of 17 vertical layers ( 9 below $1500 \mathrm{~m}$ ). The physic options presently applied in MM5 are: the first order MRF turbulence closure scheme (Hong 
and Pan, 1996), a 5-layer soil model with prescribed landuse dependent soil moisture availability, a cloud interactive radiation scheme, and explicit moist physics including the ice phase but with no parameterisation of cumulus and shallow convection. Topography and 16 land use classes, of which one is defined as urban, are collected from the U.S. Geological Survey (USGS). At $60^{\circ}$ north this data has a $0.5 \mathrm{~km} \times 0.9 \mathrm{~km}$ horizontal resolution, thus allowing a model horizontal resolution down to $1 \mathrm{~km}$.

A meteorological pre-processing interface is transforming the model output of MM5 in order to meet the input requirements of the AirQUIS modelling system. The pre-processor takes care of the following tasks:

- Horizontal and vertical interpolation of the meteorological variables from the MM5 grid to the AirQUIS grid.

- In the present version, the horizontal model domain of AirQUIS is defined as a subset of the $1 \mathrm{~km}^{2}$ MM5 model domain, with identical fields of topography and land use classification in order to avoid the use of horizontal interpolation. Vertically, MM5 applies a terrain-following coordinate, defined from an idealised hydrostatic pressure-distribution (Dudhia, 1993). In AirQUIS a similar, but not identical, terrain following $\sigma$-coordinate has now been implemented (Slørdal et al., 2003). However, since the two models are applying identical fields of topography, the model layers may be defined approximately at the same physical height, thus avoiding vertical interpolation as well.

- Meteorological input variables transferred from MM5:

- 3-D: Horizontal wind components and temperature;

- 2-D: Precipitation, relative humidity, cloud cover, ground temperature, dew-point temperature, topography, land-use classification, and surface roughness.

Note that the vertical velocity applied in AirQUIS is recalculated based on gridded horizontal wind fields from MM5 and the physical requirement of mass consistent (divergencefree) wind fields.

In the original forecast version the meteorological input required by AirQUIS were extracted from MM5 as if these were observed values available in the model grid system. The dispersion parameters for the air quality forecast were then calculated using traditional Monin-Obukhov similarity theory following the methods of van Ulden and Holtslag (1985), Bøhler (1996), Slørdal et al. (2003). Utilizing this theory in combination with the meteorological data extracted from MM5, quantities like the mixing height, the vertical profile functions in the surface layer, and the vertical eddy diffusivities, $K_{z}$, were estimated.

An important part of the FUMAPEX project has been to review and improve this interface program between MM5 and AirQUIS in order to describe the dispersion conditions more consistently, thereby assuring an optimum use of the meteorological information available within the MM5 model (Slørdal and Ødegaard, 2005). The modifications that have been tested are:

1. Direct application of the MM5 estimated surface fluxes of momentum, heat, and moisture, to estimate dispersion parameters like PBL height, vertical profile functions of the turbulence parameters $\left(\sigma_{v}\right.$ and $\left.\sigma_{w}\right)$ and the vertical eddy diffusivity $K_{z}$.

2. Direct application of the MM5 estimated PBL height and vertical eddy diffusivities (for either momentum or heat) in the dispersion model.

3. Same as point 2 above, but with application of other choices of turbulence schemes (including higher order closure) optionally available as part of the MM5 package.

Of these alternatives, the direct use of the MM5 estimated eddy diffusivities and PBL height (points 2 and 3 above) represents the closest coupling of the two model systems and should therefore be the preferred method. If improved "urbanisation" or "topographical" parameterisations are later incorporated into the NWP model, the effect of these parameterisations will directly influence the air quality forecast, and need not be "re-programmed" in the interface module.

The air quality forecast of the Oslo UAQIFS is made by the PC-based Air Quality Information System, AirQUIS (Bøhler and Sivertsen, 1998; Slørdal et al., 2003; AirQUIS, 2005). This system has been developed at NILU over the last years and has been applied for estimating urban Air Quality in several cities (Laupsa and Slørdal, 2003; Wind et al., 2003). The combination of functionalities for emission inventories and numerical modelling within a GIS platform makes AirQUIS an effective UAQIFS tool.

The AirQUIS emission inventory module contains data such as fuel consumption, emission factors, physical description of stacks and processes, traffic load, vehicle composition, road slope, etc. Estimates of hourly emissions of the different air quality components are then calculated by application of an emission model. The emission data are split into three separate categories. These are point source emissions, line source emissions and area (or grid distributed) emissions. The method applied to calculate the $\mathrm{PM}_{10}$ emissions from traffic-induced re-suspension, takes into account the effect of vehicle composition, traffic speed and, during the winter season, the percentage of vehicles with studded tyres, on each road segment. Since practically no coarse particles are re-suspended when the roads are wet, hourly MM5data on relative humidity, dew-point temperature and precipitation are included as input to the emission model.

The dispersion model within AirQUIS is an Eulerian grid model with embedded subgrid line and point source Gaussian models for near source treatment (Slørdal et al., 2003). 


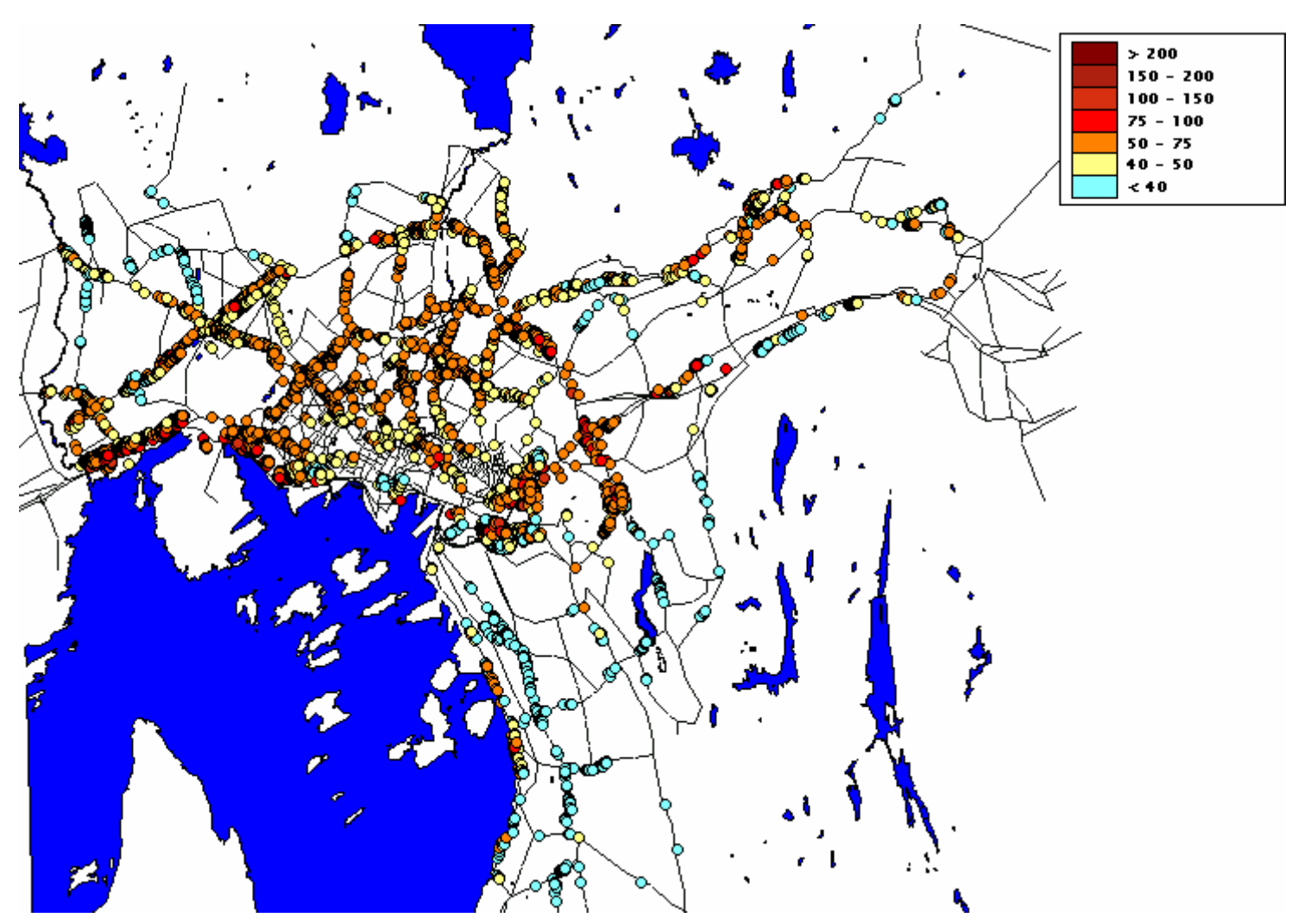

Fig. 4. Example of hourly concentration distribution of $\mathrm{PM}_{10}$ in the selected "building points" $\left(\mu \mathrm{g} / \mathrm{m}^{3}\right)$.

The model estimates urban background concentration levels in the Eulerian grid system, and near source concentrations from road transport (line sources) and individual stacks (point sources) in individual receptor points. Applying this model system, air quality forecasts are carried out for $\mathrm{NO}_{2}$, $\mathrm{PM}_{10}$, and $\mathrm{PM}_{2.5}$. At present deposition (dry or wet) is not explicitly included as a sink term in these calculations. Tests performed with inclusion of deposition for $\mathrm{PM}_{10}$ revealed that this process had negligible effect on the calculated ambient concentration levels within the urban area (Slørdal et al., 2004). The regional background is taken into account by applying climatological values of $\mathrm{NO}_{2}, \mathrm{O}_{3}, \mathrm{PM}_{10}$, and $\mathrm{PM}_{2.5}$ at the open model boundaries. Presently AirQUIS treats $\mathrm{PM}_{10}$, and $\mathrm{PM}_{2.5}$ as inert species. The contributions from secondary aerosols are assumed to be included in the applied climatological background. For the prediction of $\mathrm{NO}_{2}$, however, AirQUIS makes use of the photostationary state assumption, i.e. an instantaneous equilibrium is assumed between the three reactions relating $\mathrm{NO}, \mathrm{NO}_{2}$ and $\mathrm{O}_{3}$. By applying this assumption the three components $\mathrm{NO}, \mathrm{NO}_{2}$ and $\mathrm{O}_{3}$ may be determined by solving a second-order equation in $\mathrm{O}_{3}$, and the ambient concentration of $\mathrm{NO}_{2}$ is found by subsequent insertion. During wintertime in Nordic cities, this is a rather good approximation to the real situation. However, when the solar UV-radiation is stronger, either because of a more southern location or in summer, a net ozone formation may take place even in urban areas at a certain distance from the main emission sources. Thus, the photostationary state assumption is then not valid and a more detailed chemical description is needed.

The Oslo UAQIFS also contains a population exposure module (Laupsa and Slørdal, 2003). This module, which is an integrated part of AirQUIS, combines the calculated outdoor concentration levels with information on the geographical distribution of the city inhabitants. The applied population distribution is stationary and based on information on the number of people living in each of the buildings within the city area. This corresponds to the deterministicstatistical approach described in Table 1. The application of the sub-grid line source model makes it possible to estimate more detailed concentration levels in receptor points in the vicinity of the major road network. These receptor points are placed in the geographical positions of buildings located close to the main road network (within a distance less than 200-500 $\mathrm{m}$ from the road). In AirQUIS these receptor points are termed "building points". An example of a "building point" concentration distribution is shown in Fig. 4. The colour coding indicates outdoor concentration level (in $\mu \mathrm{g} / \mathrm{m}^{3}$ ) estimated at each building position. The near road exposure levels are thus obtained simply by combining the information on building inhabitants with the estimated outdoor "building point" concentration. Exposure levels for 


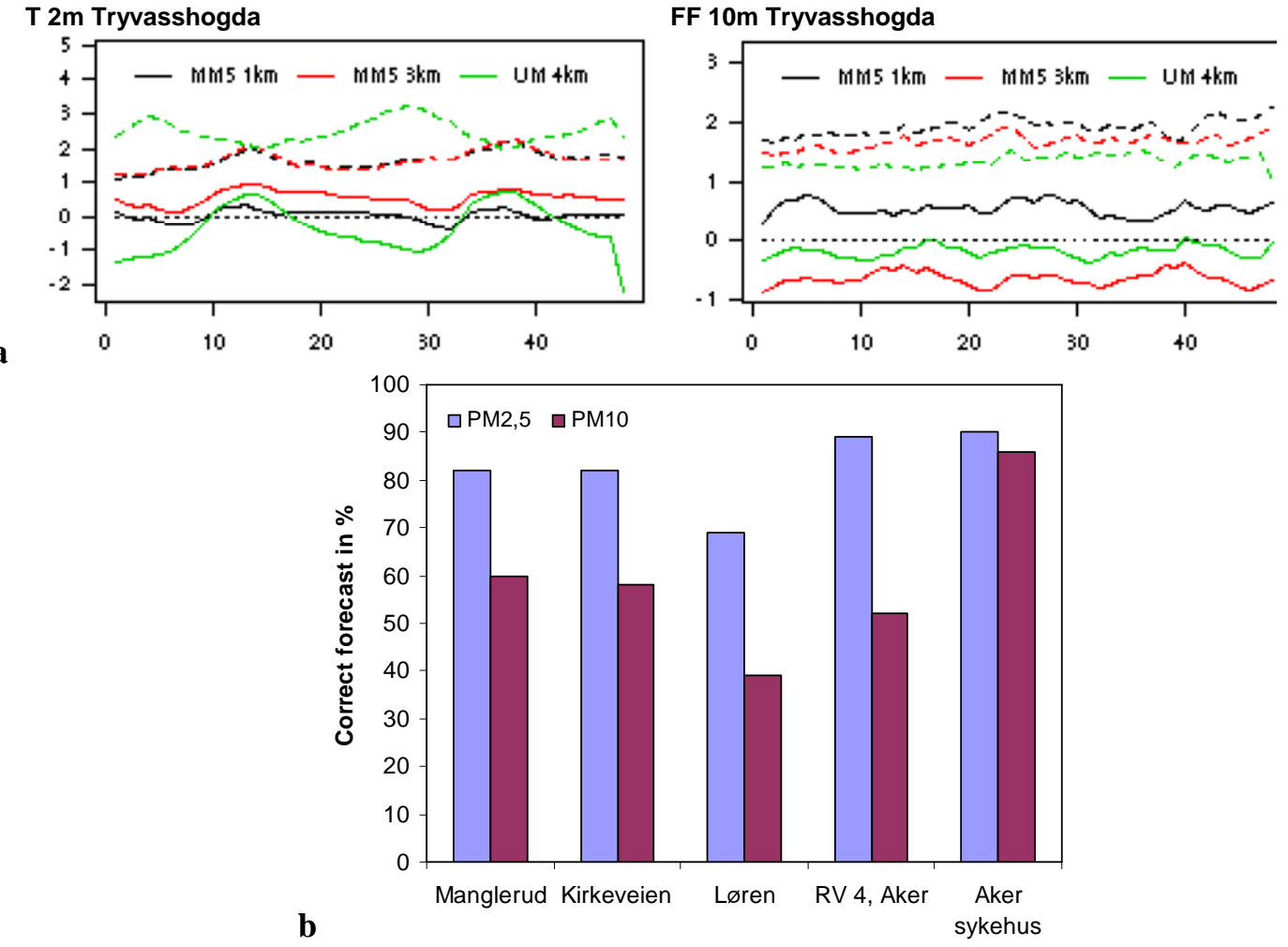

Fig. 5. Long term evaluation of the Oslo UAQIFS for the winter season (November-May) 2004-2005: (a) Forecasts of $2 \mathrm{~m}$ temperature, ${ }^{\circ} \mathrm{C}$ (left) and $10 \mathrm{~m}$ wind speed, $\mathrm{m} / \mathrm{s}$ (right) for the Oslo monitoring station Tryvasshogda. Standard deviation of error (broken lines) and bias (solid lines) as function of forecast length. Results are shown for MM5 1 km resolution (black), MM5 3 km resolution (red) and UM $4 \mathrm{~km}$ resolution (green). (b) Percentage of correct AirQUIS forecasts of $\mathrm{PM}_{2.5}$ and $\mathrm{PM}_{10}$ for five monitoring stations in the Oslo area. The diagrams are calculated for daily means of $\mathrm{PM}_{2.5} / \mathrm{PM}_{10}$ and for four warning classes. Forecasts for +24 to +48 are used in this validation. Data from the yearly evaluation report (Ødegaard et al., 2005).

inhabitants living in buildings located farther away from the main road network, i.e. buildings not defined as an individual receptor points, are defined as the Eulerian grid point concentrations (urban background) for the grid cells hosting the buildings. In this way an exposure level is estimated for the total population.

The models within the Oslo UAQIFS are run from 00:00 UTC and 48 $\mathrm{h}$ ahead, MM5 on a 40-node Linux cluster and AirQUIS on a dedicated PC, and they are coupled offline through a meteorological pre-processor interface program. Since reduced air quality is mainly a wintertime problem in Nordic cities, the integrated system is operational from October through April and daily forecasts are made for $\mathrm{NO}_{2}, \mathrm{PM}_{10}$, and $\mathrm{PM}_{2.5}$.

The time frame of the operational forecast procedure is: 04:30 local time - the HIRLAM10 prediction is ready, 05:30 - the MM5 urban-scale NWP output is available, 06:30 the AirQUIS air quality and population exposure forecast is finished. At 07:30 latest, the 06:30 - model output plots, and met.no's duty forecaster's comments on the weather situation are available on the web for the end-users.
The exposure estimates are actively used when assessing the air quality forecasts. The air quality is defined in four classes: good, moderate, poor and very poor. The concentration limits defining the various air quality classes are presented for the compounds $\mathrm{NO}_{2}$ (hourly average), $\mathrm{PM}_{10}$ (daily average) and $\mathrm{PM}_{2.5}$ (daily average) in Table 2. By combining the forecasted concentration levels (calculated both in "building points" and in the model grid system) with the population distribution, the number of inhabitants exposed within the various Air Quality classes can be estimated. An example of this type of exposure forecast is presented in Table 3.

In the Oslo UAQIFS it has been decided that at least 20000 inhabitants need to be exposed to a certain air quality class, in order to define the general air quality belonging to this class. In the example presented in Table 3, poor, moderate and good air quality is thus expected with regards to $\mathrm{PM}_{10}$, $\mathrm{PM}_{2.5}$ and $\mathrm{NO}_{2}$, respectively. In this case the overall air quality can be forecasted as poor, with an additional description of pollution type, and where (and possibly when) to expect the worst conditions.

Based on the above model results, monitoring data (air quality and meteorology) and experience, the person 
Table 2. Concentration levels defining the AQ classes for $\mathrm{NO}_{2}$, $\mathrm{PM}_{10}$ and $\mathrm{PM}_{2.5}$.

\begin{tabular}{lccc}
\hline $\begin{array}{l}\text { Air Quality } \\
\text { description }\end{array}$ & $\begin{array}{c}\mathrm{NO}_{2} \text { (Hourly) } \\
\left(\mu \mathrm{g} / \mathrm{m}^{3}\right)\end{array}$ & $\begin{array}{c}\mathrm{PM}_{10} \text { (Daily) } \\
\left(\mu \mathrm{g} / \mathrm{m}^{3}\right)\end{array}$ & $\begin{array}{c}\mathrm{PM}_{2.5} \text { (Daily) } \\
\left(\mu \mathrm{g} / \mathrm{m}^{3}\right)\end{array}$ \\
\hline Good & $0-100$ & $0-35$ & $0-20$ \\
Moderate & $100-150$ & $35-50$ & $20-35$ \\
Poor & $150-200$ & $50-100$ & $35-60$ \\
Very poor & $>200$ & $>100$ & $>60$ \\
\hline
\end{tabular}

responsible for the air quality forecast at the Oslo Public Health Agency (end-user) formulates an air quality bulletin that is published on the Internet for the general public. An example of such a bulletin is presented in Appendix A.

Validation of the operational Oslo UAQIFS was done vs. five meteorological and air quality stations in the Oslo area for the 2003/4 and 2004/5 winter seasons (Ødegaard et al., 2005). Meteorological forecast improvements due to model downscaling for the urban areas were analysed first in Berge et al. (2002) and Baklanov et al. (2002) showing significant improvements of especially the wind velocity when downscaling from $10 \mathrm{~km}$ grid operational HIRLAM model to 3 and $1 \mathrm{~km}$ grid by MM5. Further analysis by Ødegaard et al. (2005) cf. Fig. 5a show that in general the forecast of wind velocity is better using the downscaled UK MetOffice UM model (4 km resolution) than using MM5 with higher resolution. The most probable reason of that is that the UM model has more sophisticated physics and better urbanisation. For 2 meter temperature the MM5 forecast in general is slightly better than the UM $4 \mathrm{~km}$ forecast. Figure $5 \mathrm{~b}$ is showing the evaluation of the AirQUIS forecasts of $\mathrm{PM}_{2.5}$ and $\mathrm{PM}_{10}$ for five monitoring stations in the Oslo area for the winter 2004/2005. Especially for $\mathrm{PM}_{2.5}$ the number of correct forecast is fairly high from $69 \%$ to $90 \%$. For $\mathrm{PM}_{10}$ the numbers are relatively lower and with a large spread, from $38 \%$ at Løren to $86 \%$ at Aker Sykehus.

\subsection{Copenhagen emergency decision-support system}

The Danish nuclear emergency preparedness involves the Accident Reporting and Guidance Operational System (ARGOS), developed by the Danish Emergency Management Agency (DEMA) and collaborators (Hoe et al., 1999, 2002). The overall ARGOS system consists of various parts as depicted in Fig. 6.

The ARGOS system utilises meteorological forecast data for the prediction of contamination, doses and other consequences on local and European scales. In Denmark such data are provided by the Danish Meteorological Institute (DMI) four times a day. The 3-D data, which are transferred online to DEMA, are operationally extracted with $5 \mathrm{~km}$ (or experimentally $1.4 \mathrm{~km}$ ) horizontal resolution forecasting up to $54 \mathrm{~h}$
Table 3. Example of forecasted population exposure.

\begin{tabular}{lccc}
\hline $\begin{array}{l}\text { Air Quality } \\
\text { description }\end{array}$ & $\begin{array}{c}\mathrm{NO}_{2} \text { Number of } \\
\text { persons exposed }\end{array}$ & $\begin{array}{c}\mathrm{PM}_{10} \text { Number of } \\
\text { persons exposed }\end{array}$ & $\begin{array}{c}\mathrm{PM}_{2.5} \text { Number of } \\
\text { persons exposed }\end{array}$ \\
\hline Good & 491926 & 352636 & 408764 \\
Moderate & 13374 & 105565 & 96234 \\
Poor & 554 & 45255 & 856 \\
Very poor & 0 & 2398 & 0 \\
\hline
\end{tabular}

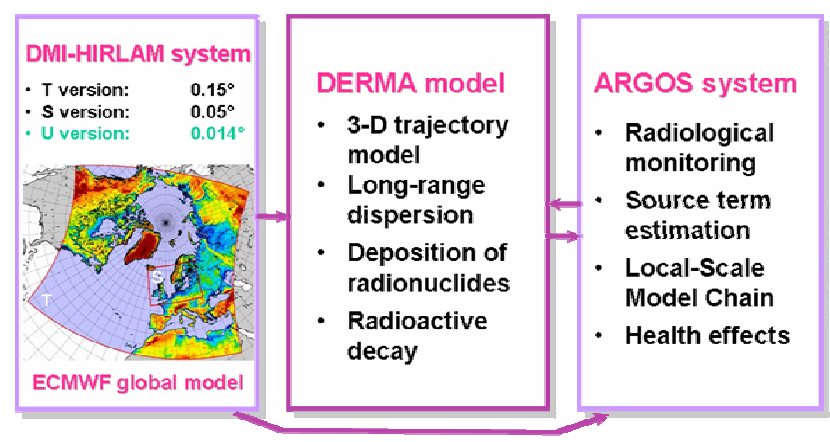

Fig. 6. Structure of the Danish nuclear emergency modelling system.

ahead. For Denmark the recent Danish operational NWP system (Sass et al., 2002) consists of two nested models named DMI-HIRLAM-S05 and -T15, with horizontal resolutions of about 5 and $15 \mathrm{~km}$, respectively. The vertical resolution of the operational versions is given by 40 levels, but for tests it has been increased to 60 vertical levels. Within the FUMAPEX project for the urban version of the ARGOS system, DMI has run several experimental versions of DMIHIRLAM over Denmark and the Zealand island on which the city of Copenhagen is located with a horizontal resolution of $1.4 \mathrm{~km}$ and improvements of parameterisations of the urban sublayer processes and the urban physiographic data classification (cf. Baklanov et al., 2005a, b).

In order to meet the input requirements of the ARGOS system, a meteorological pre-processing interface is translating and interpolating the NWP model output. The Local Scale Model Chain (LSMC) (Mikkelsen et al., 1997) comprises a meteorological pre-processor, which calculates deposition and stability parameters and wind fields based on the data provided by the DMI-HIRLAM model. These data are pre-processed and interpolated to yield data input fields for the RIMPUFF local-scale dispersion model of ARGOS. Typically the fields are interpolated to a grid spacing of about $1 \mathrm{~km}$ or finer. The wind fields are interpolated either with the linearized flow model LINCOM (Mikkelsen et al., 1997; Astrup et al., 1996) or by $1 / r^{2}$ weighting. In order to provide a more detailed wind field near the source, LINCOM is only used out to about $15 \mathrm{~km}$ from the source. The mixing height which is one of the important characteristics for UAQ 


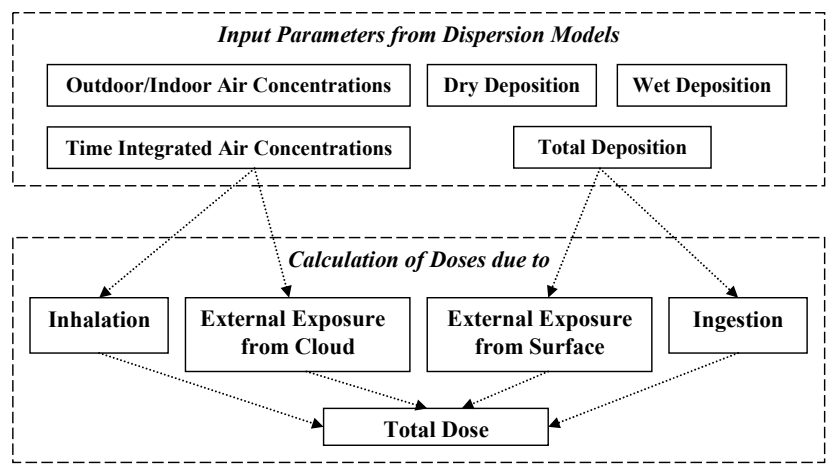

Fig. 7. General scheme of individual dose calculations for different groups of the population from radioactive airborne contamination in the ARGOS system.

models, is included in the NWP output data or calculated separately by methods suitable for urban conditions (Sørensen et al., 1996; Zilitinkevich and Baklanov, 2002; Baklanov, 2002). However, the mixing height calculation may also be realised by the LSMC using different methods.

The LSMC is used in ARGOS for the calculation of actual and forecasted ground-level air concentrations, wet and dry deposition, and ground-level gamma dose rates on short and medium range scales (up to about $100 \mathrm{~km}$ from the source). It includes the atmospheric local-scale dispersion model RIs $\varnothing$ Mesoscale PUFF model (RIMPUFF) developed at the Ris $\varnothing$ National Laboratory (Mikkelsen et al., 1984, 1997). At distances greater than about $20 \mathrm{~km}$ from the source, the DMI long-range atmospheric dispersion model, the Danish Emergency Response Model of the Atmosphere (DERMA), can be used (Sørensen, 1998; Sørensen et al., 1998; Baklanov and Sørensen, 2001). Source terms for specific events, reactors and release categories are defined in the ARGOS database. Presently the nuclide database contains 361 radionuclides. The result of the forecast includes nuclide specific air concentrations, ground contamination and gamma doses.

RIMPUFF is a fast puff diffusion code suitable for realtime simulation of puff and plume dispersion using meteorology changing in space and time. The model is provided with a puff splitting feature to deal with plume bifurcation and flow divergence due to channelling, and slope flow and inversion effects in non-uniform terrain. In RIMPUFF the puff diffusion processes are controlled by local turbulence levels, either provided directly from on-site measurements, or via pre-processor calculations. RIMPUFF is equipped with standard plume rise formulas, inversion and ground level reflections, as well as gamma dose algorithms.

DERMA is a three-dimensional Lagrangian long-range dispersion model using a puff diffusion parameterisation, particle-size dependent deposition parameterisations and radioactive decay. Earlier comparisons of simulations with the DERMA model versus the ETEX experiment involving passive tracer measurements gave very good results (Graziani et al., 1998). The DERMA model can be used with different sources of NWP data, including the DMI-HIRLAM limitedarea and the ECMWF global NWP models with various resolutions. The main objective of DERMA is the prediction of the atmospheric transport, diffusion, deposition and decay of a radioactive plume within a range from about $20 \mathrm{~km}$ from the source up to the global scale. DERMA is run on operational computers at DMI. The integration of DERMA in ARGOS is effectuated through automated on-line digital communication and exchange of data. The calculations are carried out in parallel for each NWP model to which DMI has access, thereby providing a mini-ensemble of dispersion forecasts for the emergency management.

In order to consider the micro-scale processes in urban areas (e.g., the dispersion of the released substance in a separate street canyon or around a block of buildings), a further level of nesting/downscaling can be included with usage of local-scale obstacle-resolving urban models, which have to carefully resolve the geometry of each building, e.g. the UK Urban Dispersion Model (UDM) (Brook et al., 2003). Such potential for local-scale urban simulation in the ARGOS system is considered by Thykier-Nielsen and Roed (2003).

Due to the focus of the Copenhagen system on emergency preparedness, calculation of the population exposure in ARGOS has considerable specifics. First, mostly potential radioactive releases are considered, thus the individual and collective doses for population exposure (corresponding to the deterministic-individual and deterministic-statistical approaches in Table 1) are calculated for the acute phase and long-term effects. In a general sense the total doses to man for different groups of the population (e.g., adult, children, elderly) may be calculated based on the contributions of inhalation, external exposure, and ingestion (Fig. 7).

Inhalation exposures and body depositions are estimated for subjects passing through the radioactive cloud. The deposition fields are further used to calculate soil contamination and effects of accumulation in crops and the human food chain. ARGOS calculates external doses separately for adults and children. Effective doses, inhalation doses, thyroid doses and doses avertable by shielding are calculated. The dose calculations can be carried out by different methods including gamma dose rate measurements, air concentrations of specific radionuclides, from estimated external gamma doses, and modelling of food chain effects (Hoe et al., 2000). Urban surface data bases, implemented into ARGOS, have resolutions up to $2 \mathrm{~m}$ resolving individual buildings. Population data bases in the current version of ARGOS have much poorer resolution, but it will be essentially improved for Danish cities soon.

In case of an accident or other type of emergency the ARGOS system provides air concentration, deposition, gamma dose fields, and total doses for the population. This information will be available to decision makers. The first ARGOS forecast is usually available $15-30 \mathrm{~min}$ after the information about the event was received. 


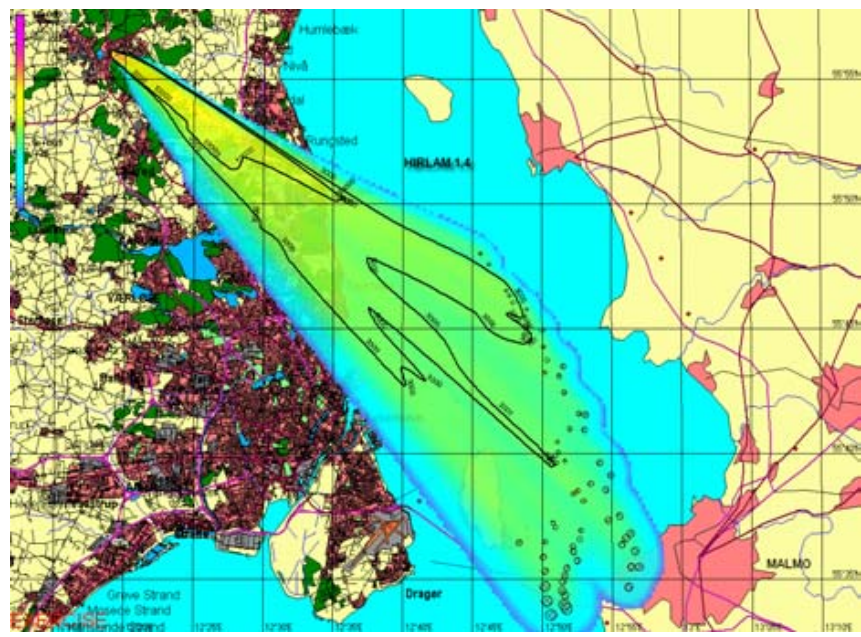

(a)

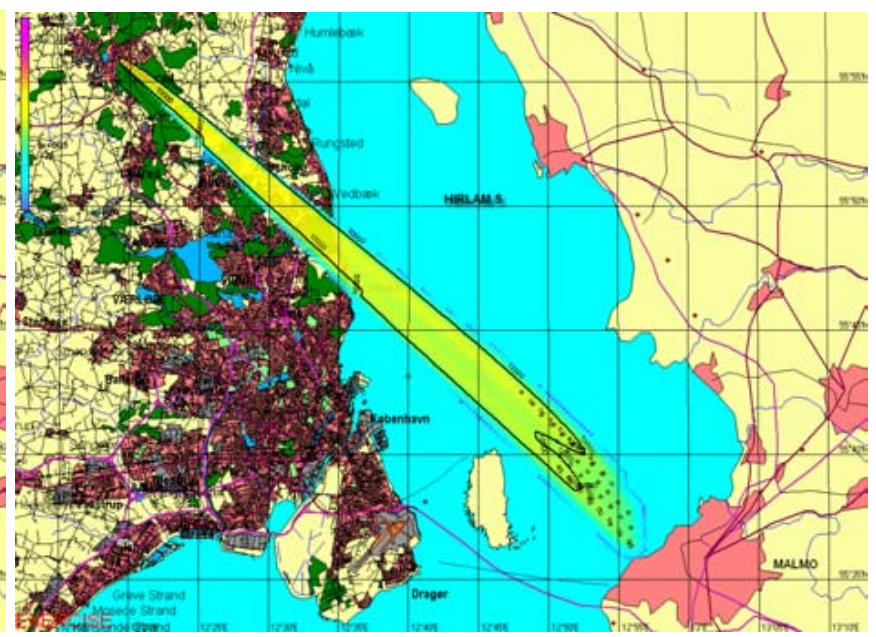

(b)

Fig. 8. A local-scale plume from the ${ }^{137}$ Cs hypothetical atmospheric release in Hillerød at 00:00 UTC, 19 June 2005 as calculated with RIMPUFF using DMI-HIRLAM and visualised in ARGOS for the Copenhagen Metropolitan Area. Cs-137 air concentration for different DMI-HIRLAM data: (a) urbanised U01, $1.4 \mathrm{~km}$ resolution, (b) operational S05, $5 \mathrm{~km}$ resolution.

Due to the specific characteristics of the Copenhagen UAQIFS regarding its application to emergency preparedness for accidental atmospheric releases, operational system validation was realized only for the meteorological part. The validation of the improved and down-scaled DMI-HIRLAM model (U01-version with $1.4 \mathrm{~km}$ resolution) for the Copenhagen area for May 2005 was considered by Baklanov et al. (2005a)(see e.g. Fig. 2 ibid.) and Mahura et al. (2005) showing an improvement of the forecasted wind fields and 2-m temperature vs. the operational S05 version with $5 \mathrm{~km}$ resolution. As shown, the diurnal cycle of the average wind velocity at $10 \mathrm{~m}$ height above ground was better predicted by the U01 model compared with S05. The maxima of wind velocity were observed in the middle of the day corresponding to $6.4(6.4)$ vs. $6.1 \mathrm{~m} / \mathrm{s}$ for the U01 (S05) models vs. observational data. The minima were observed at night corresponding to $3.5(4.1)$ vs. $3.6 \mathrm{~m} / \mathrm{s}$ for the U01 (S05) models vs. observational data. Validation and intercomparisons of the individual dispersion models integrated in, or interfaced with, the ARGOS system were carried out for specific experimental studies for other areas, e.g. ETEX, Algeciras, ENSEMBLE (Mikkelsen et al., 1997; Sørensen et al., 1998; Galmarini et al., 2004a, b; Baklanov et al., 2005b) showing realistic simulation results.

To demonstrate the improved ARGOS system for the Copenhagen metropolitan area, let us consider a hypothetical dirty bomb scenario, as described by Sohier and Hardeman (2005), with radioactive releases from the town of Hillerød close to Copenhagen city. The source was Cs-137 released at a constant rate of $10^{11} \mathrm{~Bq} / \mathrm{s}$ within $15 \mathrm{~min}$. The information about the source term for a dirty bomb scenario is a very uncertain issue. In this sensitivity study we consider a unit release of ${ }^{137} \mathrm{Cs}$ as an example. It could be considered as the first stage of forecasting for later adaptation when relevant data about the release strength become available. For the situation considered on 19 June 2005, the hypothetical release took place from 00:00 to 00:15 UTC. In Fig. 8 the corresponding local-scale plume from the hypothetical atmospheric release of ${ }^{137} \mathrm{Cs}$, as calculated by RIMPUFF/ARGOS using meteorological data from the urbanised U01 and operational S05 DMI-HIRLAM models and visualised by ARGOS, is shown for the Copenhagen metropoli$\tan$ area. $250 \mathrm{~m}$ resolution land orography data were used for the ARGOS simulations. Figure 9 shows the differences in the mixing heights, simulated for the two versions of DMIHIRLAM (urbanised U01 and operational S05) and considered in the above ARGOS simulations. The urban heat island effect, considered by the urbanised version U01, on MH over Copenhagen, Malmö and other Danish and Swedish cities (marked by arrows) is very visible in Fig. 9a. The mixing height considerably affects the air concentration and deposition levels of the contaminants.

The sensitivity of the dispersion pattern on the meteorological data (operational non-urbanised 5-km S05 and cityscale 1.4-km urbanised U01) is large: the differences in dispersion, as seen in Fig. 8, lead to different levels of contamination over the city areas and to different areas contaminated by the plume. Finally, the sensitivity of the population exposure (doses) to the urban improvements in the DMIHIRLAM model, used for the ARGOS simulations, have been studied. The collective doses for populations of different towns and areas of Copenhagen are very different for the non-urbanised operational S05 and for urbanised 1.4-km resolution U01 due to the urban effects considered, i.e. 10.1 


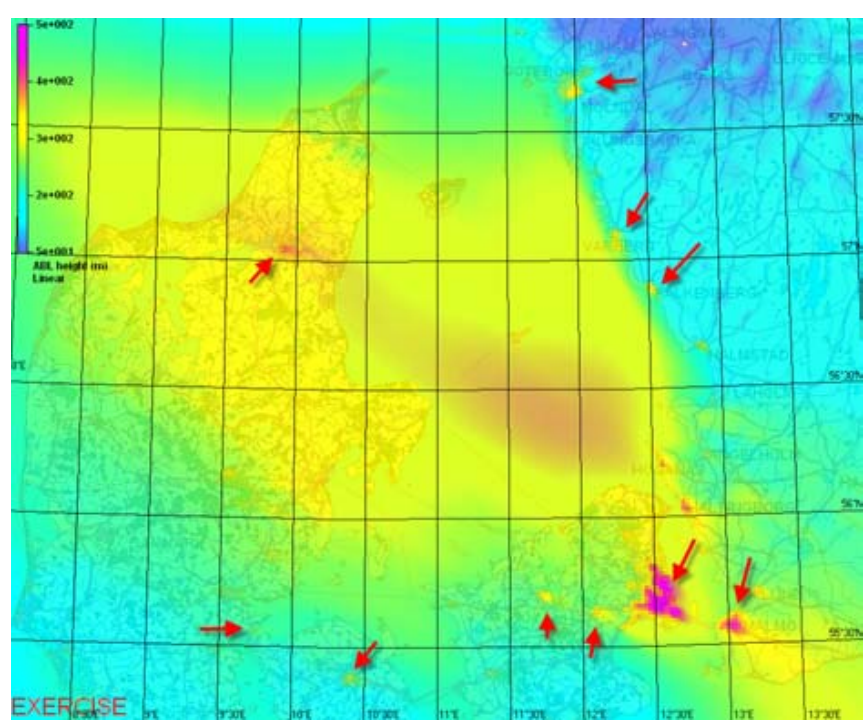

(a)

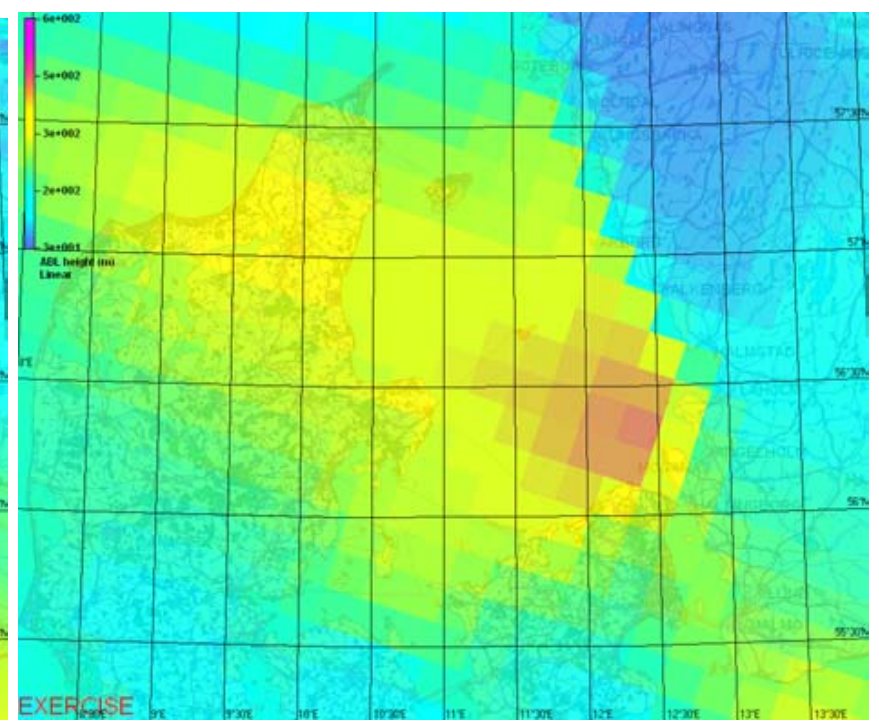

(b)

Fig. 9. The mixing height for a large part of Denmark as calculated from different versions of DMI-HIRLAM: (a) urbanised U01, (b) operational T15. Main cities are shown by arrows.

and 1.89 (in relative units) for the city of Hørsholm, and 7.16 and 2.72 for Birkerød.

\section{Conclusions}

Urban areas modify significantly many parameters that affect micrometeorology, including surface roughness, moisture, albedo and, correspondingly, dynamical and thermal structures in the urban boundary layer. They are additionally affected by heating and other energy consuming processes acting as anthropogenic energy sources. A large fraction of anthropogenic emissions to the atmosphere also occur within this very same area, where also a large majority of the western populations are located. Until now air quality models have been unable to reliably estimate air pollution levels especially during the events with the most urgent need for reliable information, namely the air pollution episodes.

Latest improvements in numerical weather prediction models allow the inclusion of urban area features and therefore describe the state of the urban mixing layer more realistically than ever before. This is an essential prerequisite for reliable air quality modelling in urban areas.

Urban populations are mobile throughout their daily activities. Large fractions of the population concentrate on traffic arteries during the rush hours, when the air quality especially in these environments is the poorest. People concentrate in downtown areas during the daytime simultaneously when the air quality is lowered through traffic and other emissions. On the other hand, urban populations spend large fractions of their time in indoor environments, where the building partly shields them from the pollution in the ambient air. These phenomena have profound effects on actual population exposures within cities and should be accounted for when evaluating air quality and planning actions aiming at protection of the public health.

FUMAPEX demonstrates the integration of numerical weather prediction with air quality modelling systems in six target cities and combines such urban air quality information and forecasting systems (UAQIFS) with the modelling of population exposures during episode conditions. Such an integrated UAQIFS allows for reliable air quality and exposure forecasting and supports effective decision-making in short-term air quality management and emergency preparedness. Additionally, these systems are valuable tools in longterm city planning for the optimisation of urban environments in terms of minimised population exposure and associated health risks.

Applications of the suggested integration strategy and improved UAQIFS are demonstrated in the three Nordic capitals considered: urban air pollution episode forecasts and assessments for Helsinki and Oslo, and urban emergency preparedness modelling for Copenhagen. 
Appendix A

\section{Forecast of air quality Oslo Public Health and Welfare Agency}

\section{Forecast for Oslo:}

- The air quality was moderate Sunday 7 December at 9 a.m. The air quality is expected to be moderate within Ring road 2 and along the main roads in the morning. It is dust resuspension and wood burning that causes the pollution. The air quality is expected to be good in other parts of the city.

- Forecast for Monday 8. December. The air quality is expected to be poor to very poor along the main roads. The highest concentrations can be expected during the rush hours. The air quality is expected to be moderate within Ring road 3 and in greater distance to the main roads. It is dust re-suspension and exhaust that causes the pollution. The air quality is expected to be good in other parts of the city.
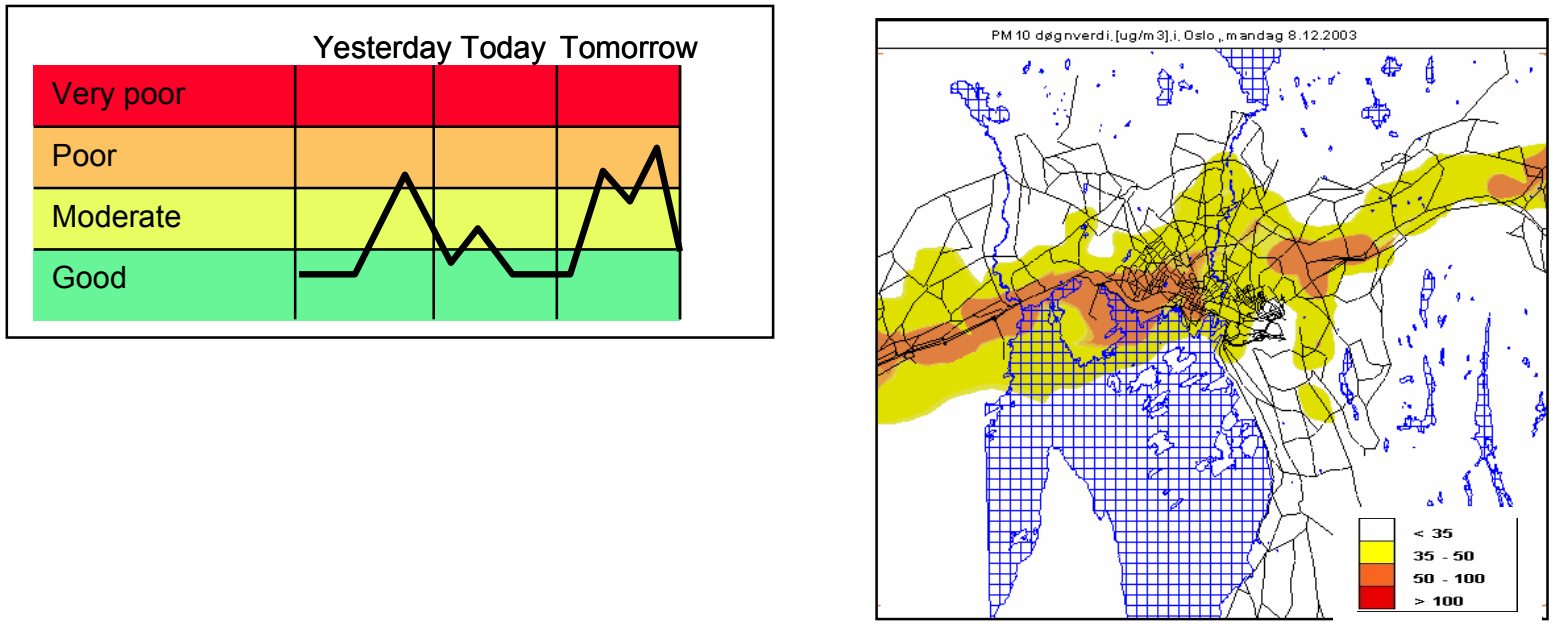

\begin{tabular}{ll}
\hline Level & Health Effects \\
\hline Good & No health effects \\
\hline Moderate & $\begin{array}{l}\text { Asthmatics may experience health effects in these areas, especially during } \\
\text { physical activities. }\end{array}$ \\
\hline Poor & $\begin{array}{l}\text { Asthmatics and people with serious heart- and bronchial diseases should avoid } \\
\text { longer outdoor stays in areas with poor air quality. }\end{array}$ \\
\hline Very poor & $\begin{array}{l}\text { Asthmatics and people with serious heart- and bronchial diseases should avoid } \\
\text { areas with very poor air quality. Healthy people may experience incidentally irritations } \\
\text { in the muscular membrane and unpleasantness. }\end{array}$ \\
\hline
\end{tabular}

Fig. A1. Example of an air quality bulletin for Oslo (8 December 2003) published on the Internet by the Oslo Public Health Agency. 
Acknowledgements. Financial support of this study came from EU FUMAPEX (EVK4-CT-2002-00097) project. The authors are grateful to many FUMAPEX partners and end-users for collaboration, discussions and constructive comments.

Edited by: S. Galmarini

\section{References}

AirQUIS: http://www.nilu.no/aqm/, 2005.

Astrup, P., Jensen, N. O., and Mikkelsen, T.: Surface roughness model for LINCOM, Ris $\varnothing-R-900(E N), 30$ p., 1996.

Baklanov, A.: The mixing height in urban areas - a review, Mixing heights and inversions in urban areas, COST Action 715, EC Publication EUR 20451, p. 9-28, 2002.

Baklanov, A., Rasmussen, A., Fay, B., Berge, E., and Finardi, S.: Potential and shortcomings of numerical weather prediction models in providing meteorological data for urban air pollution forecasting, Water, Air and Soil Poll.: Focus, 2, 43-60, 2002.

Baklanov, A., Mestayer, P., Clappier, A., Zilitinkevich, S., Joffre, S., Mahura, A., and Nielsen, N. W.: On the parameterisation of the urban atmospheric sublayer in meteorological models, Atmos. Chem. Phys. Discuss., 5, 12 119-12 176, 2005a.

Baklanov, A., Sørensen, J. H., Hoe, S. C., and Amstrup, B.: Urban meteorological modelling for nuclear emergency preparedness, J. Envir. Radioact., 85(2006), 154-170, 2005b.

Baklanov, A. and Sørensen, J. H.: Parameterisation of radionuclide deposition in atmospheric dispersion models, Phys. Chem. Earth, 26, 787-799, 2001.

Berge, E., Walker, S.-E., Sorteberg, A., Lenkopane, M., Eastwood, S., Jablonska, H. I., and Køltzow, M. Ø.: A real-time operational forecast model for meteorology and air quality during peak air pollution episodes in Oslo, Norway, Water, Air and Soil Pollution: Focus, 2, 745-757, 2002.

Berkowicz, R.: OSPM - A parameterised street pollution model, Environ. Monit. Assessment, 65, 323-331, 2000.

Brook, D. R., Felton, N. V., Clem, C. M., Strickland, D. C. H., Griffiths, I. H., Kingdon, R. D., Hall, D. J., and Hargrave, J. M.: Validation of the Urban Dispersion Model (UDM), Int. J. Environ. Pollut., 20, 11-21, 2003.

Bøhler, T.: MEPDIM. The NILU Meteorological Processor for Dispersion Modelling, Version 1.0, Model description, Norwegian Institute for Air Research, Kjeller (NILU TR 7/96), 1996.

Bøhler, T. and Sivertsen, B.: A modern Air Quality Management system used in Norway, Norwegian Institute for Air Research, Kjeller (NILU F 4/98), 1998.

Byun, D. W. and Ching, J. K. S. (Eds.): Science Algorithms of the EPA Models-3 Community Multiscale Air Quality (CMAQ) Modelling System, EPA/600/R-99/030, Washington, D.C., 1999.

Coulson, G., Bartonova, A., Bøhler, T., Broday, D. M., Colbeck, I., Fløisand, I., Fudala, J., Hollander, W., Housiadas, Ch., Lazaridis, M., and Smolik, J.: Exposure Risks from Pollutants in Domestic Environments: The Urban Exposure Project, Indoor Built. Environ., 14(3-4), 209-213, 2005.

Dudhia, J.: A multi-layer soil temperature model for MM5, Preprints, The sixth PSU/NCAR Mesoscale Model Users Workshop, 22-24 July 1996, Boulder, Colorado, p. 49-50, 1996.

Dudhia, J.: A nonhydrostatic version of the Penn State/NCAR mesoscale model: Validation tests and simulation of an Atlantic cyclone and cold front, Mon. Wea. Rev., 121, 1493-1513, 1993.

EC/2000/69: Directive 2000/69/EC of 16 November 2000 relating to limit values for benzene carbon monoxide in ambient air, J. Europ. Commun., L313/12, 2000.

EC/2002/3: Directive 2002/3/EC of 12 February 2002 relating to ozone in ambient air, J. Europ. Commun., L67/14, 2002.

EC/96/62: Directive 96/62/EC of September 27 on ambient air quality assessment and management, J. Europ. Commun., L296/55, 1996.

EC/99/30: Directive 99/30/EC of 22 April 1999 relating to limit values for sulphur dioxide, nitrogen dioxide and oxides of nitrogen, particulate matter and lead in ambient air, J. Europ. Commun., L163/41, 1999.

Fay, B. and Neunhäuserer, L.: Evaluation of very high-resolution simulations with the non-hydrostatic numerical weather prediction model Lokalmodell for urban air pollution episodes in Helsinki, Oslo and Valencia, Atmos. Chem. Phys., 6, 2107-2128, 2006,

http://www.atmos-chem-phys.net/6/2107/2006/.

Fay, B., Neunhäuserer, L., Palau, J. L., Perez-Landa, G., Dieguez, J. J., Oedegaard, V., Bonafe, G., Jongen, S., Rasmussen, A., Amstrup, B., Baklanov, A., and Damrath, U.: Evaluation and intercomparison of operational mesoscale models for FUMAPEX target cities, D3.4 FUMAPEX Report, DWD, Germany, 2005.

Fay, B., Neunhäuserer, L., Palau, J. L., Dieguez, J. J., Oedegaard, V., Bjergene, N., Sofiev, M., Rantamäki, M., Valkama, I., Kukkonen, J., Rasmussen, A., and Baklanov, A.: Model simulations and preliminary analysis for three air pollution episodes in Helsinki, D3.3 FUMAPEX Report, DWD, Germany, 2004.

Finardi, S. (Ed.), Baklanov, A., Clappier, A., Fay, B., Joffre, S., Karppinen, A., Ødegaard, V., Slordal, L. H., Sofiev, M., Sokhi, R. S., and Stein, A.: Improved interfaces and meteorological preprocessors for urban air pollution models, Deliverable 5.2-3 of the EC FUMAPEX project, Arianet, Milan, Italy, 97 p., 2005.

Galmarini, S., Bianconi, R., Klug, W., Mikkelsen, T., Addis, R., Andronopoulos, S., Astrup, P., Baklanov, A., Bartniki, J., Bartzis, J. C., Bellasio, R., Bompay, F., Buckley, R., Bouzom, M., Champion, H., D’Amours, R., Davakis, E., Eleveld, H., Geertsema, G. T., Glaab, H., Kollax, M., Ilvonen, M., Manning, A., Pechinger, U., Persson, C., Polreich, E., Potemski, S., Prodanova, M., Saltbones, J., Slaper, H., Sofiev, M. A., Syrakov, D., Sørensen, J. H., Van der Auwera, L., Valkama, I., and Zelazny, R.: Ensemble Dispersion Forecasting, Part I: Concept, Approach and Indicators, Atmos. Environ., 38, 4607-4617, 2004a.

Galmarini, S., Bianconi, R., Klug, W., Mikkelsen, T., Addis, R., Andronopoulos, S., Astrup, P., Baklanov, A., Bartniki, J., Bartzis, J. C., Bellasio, R., Bompay, F., Buckley, R., Bouzom, M., Champion, H., D’Amours, R., Davakis, E., Eleveld, H., Geertsema, G. T., Glaab, H., Kollax, M., Ilvonen, M., Manning, A., Pechinger, U., Persson, C., Polreich, E., Potemski, S., Prodanova, M., Saltbones, J., Slaper, H., Sofiev, M. A., Syrakov, D., Sørensen, J. H., Van der Auwera, L., Valkama, I., and Zelazny, R.: Can the Confidence in Long Range Atmospheric Transport Models Be Increased? The Pan-European Experience of ENSEMBLE, Radiat. Prot. Dosim., 109, 19-24, 2004b.

Graziani, G., Klug, W., and Moksa, S.: Real-Time Long-Range Dispersion Model Evaluation of the ETEX First Release, EU JRC, 1998.

Grell, G., Dudhia, J., and Stauffer, D.: A Description of the Fifth- 
Generation PENN STATE/NCAR Mesoscale Model (MM5), NCAR Technical Note, NCAR/TN-398+STR, Boulder, Colorado, National Center for Atmospheric Research, 138 pp., 1994.

Hänninen, O. O., Kruize, H., Lebret, E., and Jantunen, M.: EXPOLIS Simulation Model: PM2.5 Application and Comparison with Measurements in Helsinki, J. Exposure Analysis and Environ. Epidemiology, 13, 74-85, 2003.

Hänninen, O. O., Lebret, E., Ilacqua, V., Katsouyanni, K., Künzli, N., Srám, R. J., and Jantunen, M. J.: Infiltration of ambient PM2.5 and levels of indoor generated non-ETS PM2.5 in residences of four European cities, Atmos. Environ., 38(37), 64116423, 2004b.

Hänninen, O. O., Alm, S., Katsouyanni, K., Künzli, N., Maroni, M., Nieuwenhuijsen, M. J., Saarela, K., Sram, R. J., Zmirou, D., and Jantunen, M. J.: The EXPOLIS Study: Implications for exposure research and environmental policy in Europe, Journal of Exposure Analysis and Environmental Epidemiology, 14, 440456, 2004a.

Hänninen, O. O., Lebret, E., Tuomisto, J. T., and Jantunen, M. J.: Characterization of model error in the simulation of PM2.5 exposure distributions of the working age population in Helsinki, Finland, J. Air \& Waste Manage. Assoc., 55, 446-457, 2005.

Jantunen, M. J., Hänninen, O. O., Katsouyanni, K., Knöppel, H., Künzli, N., Lebret, E., Maroni, M., Saarela, K., Srám, R. J., and Zmirou, D.: Air pollution exposure in European cities: The EXPOLIS-study, Journal of Exposure Analysis and Environmental Epidemiology, 8(4), 495-518, 1998.

Härkönen, J.: Regulatory dispersion modelling of traffic-originated pollution, Finnish Meteorological Institute, Contributions No. 38, FMI-CONT-38, ISSN 0782-6117, University Press, Helsinki, 103 p., 2002.

Hoe, S., Sørensen, J. H., and Thykier-Nielsen, S.: The Nuclear Decision Support System ARGOS NT and Early Warning Systems in Some Countries around the Baltic Sea, Proceedings of the 7th Topical Meeting on Emergency Preparedness and Response, 1417 September 1999, Santa Fe, New Mexico, USA, 1999.

Hoe, S., Müller, H., and Thykier-Nielsen, S.: Integration of dispersion and radioecological modelling in ARGOS NT, Proceedings of IRPA 10, Tenth International Congress of the International Radiation Protection Association, Hiroshima, Japan, 14-19 May 2000

Hoe, S. C., Müller, H., Gering, F., Thykier-Nielsen, S., and Sørensen, J. H.: ARGOS 2001 a Decision Support System for Nuclear Emergencies, in: Proceedings of the Radiation Protection and Shielding Division Topical Meeting, 14-17 April 2002, Santa Fe, New Mexico, USA, 2002.

Hong, S.-Y. and Pan, H.-L.: Nonlocal boundary layer vertical diffusion in a medium range forecast model, Mon. Wea. Rev., 124, 2322-2339, 1996.

Järvenoja, S.: A new meso- $\beta$-scale HIRLAM system at FMI, HIRLAM Newsletter, 47, 91-106, 2005.

Kangas, M. and Sokka, N.: Operational RCR HIRLAM at FMI, HIRLAM Newsletter, 48, 14-20, 2005.

Karppinen, A., Joffre, S., and Vaajama, P.: Boundary layer parametrization for Finnish regulatory dispersion models, Int. J. Environ. Pollut., 8, 557-564, 1997.

Karppinen, A., Kukkonen, J., Elolähde, T., Konttinen, M., Koskentalo, T., and Rantakrans, E.: A modelling system for predicting urban air pollution, Model description and applications in the Helsinki metropolitan area, Atmos. Environ., 34, 3723-3733, 2000a.

Karppinen, A., Kukkonen, J., Elolähde, T., Konttinen, M., and Koskentalo, T.: A modelling system for predicting urban air pollution, Comparison of model predictions with the data of an urban measurement network, Atmos. Environ., 34, 3735-3743, $2000 b$.

Karppinen, A., Joffre, S. M., and Kukkonen, J.: The refinement of a meteorological preprocessor for the urban environment, Int. J. Environ. Pollut., 14, 565-572, 2000c.

Karppinen, A., Kauhaniemi, M., Härkänen, J., Kukkonen, J., Kousa, A., and Koskentalo, T.: Evaluation of a model for predicting fine particle concentrations, Abstract book of the conference: 2005 AAAR Particulate Matter Supersites Program and Related Studies, Abstract 10C-3, p. 84, 2005.

Koistinen, K. J., Hänninen, O. O., Rotko, T., Edwards, R. D., Moschandreas, D., and Jantunen, M. J.: Behavioral And Environmental Determinants Of Personal Exposures To PM2.5, in EXPOLIS-Helsinki, Finland, Atmos. Environ., 35(14), 2473 2481, 2001.

Kousa, A., Kukkonen, J., Karppinen, A., Aarnio, P., and Koskentalo T.: A model for evaluating the population exposure to ambient air pollution in an urban area, Atmos. Environ., 36, 2109-2119, $2002 b$.

Kousa, A., Oglesby, L., Koistinen, K., Kunzli, N., and Jantunen, M.: Exposure chain of urban air PM2.5 - associations between ambient fixed site, residential outdoor, indoor, workplace and personal exposures in four European cities in the EXPOLIS-study, Atmos. Environ., 36, 3031-3039, 2002a.

Kruize, H., Hänninen, O. O., Breugelmans, O., Lebret, E., and Jantunen, M.: Description and demonstration of the EXPOLIS simulation model: Two examples of modeling population exposure to particulate matter, J. Exposure Analysis and Environ. Epidemiology, 13(2), 87-99, 2003.

Kukkonen, J., Partanen, L., Karppinen, A., Walden, J., Kartastenpää, R., Aarnio, P., Koskentalo, T., and Berkowicz, R.: Evaluation of the OSPM model combined with an urban background model against the data measured in 1997 in Runeberg Street, Helsinki, Atmos. Environ., 37(8), 1101-1112, 2003.

Laupsa, H. and Slørdal, L. H.: Applying model calculations to estimate urban air quality with respect to the requirements of the EU directives on $\mathrm{NO}_{2}, \mathrm{PM}_{10}$ and $\mathrm{C}_{6} \mathrm{H}_{6}$, Int. J. Environ. Pollut., 20, 309-320, 2003.

Mahura, A., Baklanov, A., Petersen, C., Sattler, K., Amstrup, B., and Nielsen, N. W.: ISBA Scheme Performance in High Resolution Modelling for Low Winds Conditions, HIRLAM Newsletter 49, 22-35, 2005.

Mikkelsen, T., Thykier-Nielsen, S., Astrup, P., Santabárbara, J. M., Sørensen, J. H., Rasmussen, A., Robertson, L., Ullerstig, A., Deme, S., Martens, R., Bartzis, J. G., and Päsler-Sauer, J.: MET-RODOS: A Comprehensive Atmospheric Dispersion Module, Radiat. Prot. Dosim., 73, 45-56, 1997.

Mikkelsen, T., Larsen, S. E., and Thykier-Nielsen, S.: Description of the Ris $\varnothing$ puff diffusion model, Nuclear Technology, 67, 56-65, 1984.

Oglesby, L., Künzli, N., Röösli, M., Braun-Fahrländer, C., Mathys, P., Stern, W., Jantunen, M., and Kousa, A.: Validity of ambient levels of fine particles as surrogate for personal exposure to outdoor air pollution, J. Air \& Waste Manage. Assoc., 50, 1251- 
$1261,2000$.

Ott, W. R.: Human exposure assessment: the birth of a new science, J. Exposure Analysis and Environ. Epidemiology, 5, 449-472, 1995.

Pellizzari, E. D., Clayton, C. A., Rodes, C. E., Mason, R. E., Piper, L. L., Fort, B., Pfeifer, G., and Lynam, D.: Particulate matter and manganese exposures in Toronto, Canada, Atmos. Environ., 33, 721-734, 1999

Pohjola, M. A, Pirjola, L., Kukkonen, J., and Kulmala, M.: Modelling of the influence of aerosol processes for the dispersion of vehicular exhaust plumes in street environment, Atmos. Environ., 37(3), 339-351, 2003.

Pope, C. A., Burnett, R. T., Thun, M. J., Calle, E. E., Krewski, D., Ito, K., and Thurston, G. D.: Lung cancer, cardiopulmonary mortality, and long-term exposure to fine particulate air pollution, The Journal of the American Medical Association, 287(9), 1132-1141, 2002.

RODOS: Decision support system for off-site nuclear emergency management in Europe, edited by: Ehrhardt, J. and Weiss, A., Final project report, EC DG Research, EURATOM, EUR 19144 EN, 259 p., 2000.

Sass, B. H., Nielsen, N. W., Jørgensen, J. U., Amstrup, B., Kmit, M., and Mogensen, K. S.: The operational DMI-HIRLAM system - 2002 version, DMI Technical Report 02-05, 2002.

Samoli, E., Analitis, A., Touloumi, G., Schwartz, J., Anderson, H. R., Sunyer, J., Bisanti, L., Zmirou, D., Vonk, J. M., Pekkanen, J., Goodman, P., Paldy, A., Schindler, C., and Katsouyanni, K.: Estimating the Exposure-Response Relationships between Particulate Matter and Mortality within the APHEA Multicity Project, Env. Health Pers., 113(1), 88-95, 2005.

Slørdal, L. H. and Ødegaard, V.: Dispersion conditions in the stable boundary layer as described by the MM5-model - A case study of a pollution episode in Oslo, Norway, Proceedings of 5th International Conference on Urban Air Quality, 29-31 March 2005, Valencia, Spain, 2005.

Slørdal, L. H., Solberg, S., and Walker, S. E.: The Urban Air Dispersion Model EPISODE applied in AirQUIS 2003 , Technical description, Norwegian Institute for Air Research, Kjeller (NILU TR 12/03), 2003.

Slørdal, L. H., Laupsa, H., Wind, P., and Tarrasón, L.: Local and regional description of Particulate Matter in the Oslo, Joint MSC-W \& NILU Technical Report 5/04, Oslo, The Norwegian Meteorological Institute, http://www.emep.int/publ/reports/ 2004/emep_technical_5_2004.pdf, 2004.
Sohier, A. and Hardeman, F.: Radiological Dispersion Devices: Are we prepared? (NKS Conference on Radioactive Contamination in Urban Areas, 7-9 May 2003, Risø, Roskilde, Denmark), J. Environ. Radioact., 85(2006), 171-181, 2005.

Sokhi, R. S., Kitwiroon, N., and Luhana, L.: FUMAPEX Datasets of Urban Air Pollution Models and Meteorological Preprocessors, D2.1-2.2 report for FUMAPEX, 41 p., 2003.

Sørensen, J. H.: Sensitivity of the DERMA Long-Range Dispersion Model to Meteorological Input and Diffusion Parameters, Atmos. Environ., 32, 4195-4206, 1998.

Sørensen, J. H., Rasmussen, A., and Svensmark, H.: Forecast of Atmospheric Boundary Layer Height Utilised for ETEX Real-time Dispersion Modelling, Phys. Chem. Earth, 21, 435-439, 1996.

Sørensen, J. H., Rasmussen, A., Ellermann, T., and Lyck, E.: Mesoscale Influence on Long-range Transport; Evidence from ETEX Modelling and Observations, Atmos. Environ., 32, 4207 4217, 1998.

Thykier-Nielsen, S. and Roed, J.: Dispersion as a consequence of detonation of a dirty bomb in an urban area, NKS Conference on Radioactive Contamination in Urban Areas, 7-9 May 2003, Ris $\varnothing$, Roskilde, Denmark, 2003.

Undén, P. (Ed.): HIRLAM-5 Scientific Documentation, Available from SMHI, S-601 76 Norrköping, Sweden, 2002.

van Ulden, A. P. and Holtslag, A. A. M.: Estimation of Atmospheric Boundary Layer Parameters for Diffusion Applications, J. Appl. Meteor., 24, 1196-1207, 1985.

WHO: Air Quality Guidelines for Europe. 2., WHO Regional Publications, European Series No. 91, 2000.

Wind, P., Tarrason, L., Slørdal, L.H., Solberg, S., Denby, B., and Walker, S. E.: Development of a modelling system able to link hemispheric-regional and local air pollution. Oslo, The Norwegian Meteorological Institute (Joint MSC-W \& NILU Note2/03), http://www.emep.int/publ/reports/2003/mscw_ note_2_2003.pdf, 2003.

Zilitinkevich, S. and Baklanov, A.: Calculation of the height of stable boundary layers in practical applications, Boundary-Layer Meteorology, 105(3), 389-409, 2002.

Ødegaard, V., Gjerstad, K. I., and Bjergene, N.: Bedre byluft. Evaluering av prognosemodell for meteorologi og luftkvalitet vinteren 2004/2005, Met.no. report no. 14/2005. 